Review

\title{
Superparamagnetic Nanoparticles for Atherosclerosis Imaging
}

Fernando Herranz ${ }^{1,2, *}$, Beatriz Salinas ${ }^{1,2}$, Hugo Groult ${ }^{1,2}$, Juan Pellico ${ }^{1,2}$, Ana V. Lechuga-Vieco ${ }^{1,2}$, Riju Bhavesh ${ }^{1}$ and J. Ruiz-Cabello ${ }^{1,2,3}$

1 Advanced Imaging Unit, Department of Epidemiology, Atherothrombosis and Imaging, Spanish National Centre for Cardiovascular Research (CNIC), Melchor Fernández Almagro, 3, 28029 Madrid, Spain; E-Mails: beachinchilla@gmail.com (B.S.); hugo.groult@externo.cnic.es (H.G.); jpellico@externo.cnic.es (J.P.); anavictoria.lechuga@cnic.es (A.V.L.-V.); riju.bhavesh@cnic.es (R.B.); ruizcabe@cnic.es (J.R.-C.)

2 CIBER of Pulmonary Diseases, Biomedical Research Network, Carlos III Health Institute, 28029 Madrid, Spain

3 Department of Physicochemistry II, Faculty of Pharmacy, Complutense University Madrid (UCM), Plaza Ramón y Cajal s/n Ciudad Universitaria, 28040 Madrid, Spain

* Author to whom correspondence should be addressed; E-Mail: fherranz@cnic.es; Tel.: +34-91-4531200; Fax: +34-91-4531265.

Received: 25 March 2014; in revised form: 15 May 2014 / Accepted: 16 May 2014 / Published: 5 June 2014

\begin{abstract}
The production of magnetic nanoparticles of utmost quality for biomedical imaging requires several steps, from the synthesis of highly crystalline magnetic cores to the attachment of the different molecules on the surface. This last step probably plays the key role in the production of clinically useful nanomaterials. The attachment of the different biomolecules should be performed in a defined and controlled fashion, avoiding the random adsorption of the components that could lead to undesirable byproducts and ill-characterized surface composition. In this work, we review the process of creating new magnetic nanomaterials for imaging, particularly for the detection of atherosclerotic plaque, in vivo. Our focus will be in the different biofunctionalization techniques that we and several other groups have recently developed. Magnetic nanomaterial functionalization should be performed by chemoselective techniques. This approach will facilitate the application of these nanomaterials in the clinic, not as an exception, but as any other pharmacological compound.
\end{abstract}


Keywords: iron oxide nanoparticles; cardiovascular imaging; atherosclerosis plaque; chemoselective functionalization

\section{Introduction}

Superparamagnetic iron oxide nanoparticles (IONPs) are entering a new phase in the biomedical field, with a mushrooming spectrum of applications that no longer limits its clinical use [1]. For instance, oncological research has widely found an application of these nano-platform-based diagnosis and therapy tools, due to their specific features [2,3]. The situation for cardiovascular diseases is not that advanced yet; but, the research is quite intensive, and most researchers working in the field have realized the potential of applying nanotechnology to their work. This has translated into many results in conditions, like atherosclerotic plaque, stroke or myocardial infarction [4-8].

Figure 1. Steps in the synthesis of iron oxide nanoparticles (IONP) for preclinical atherosclerosis imaging. (A) Mixture of iron precursors and different surfactants in organic solvents; (B) Iron oxide nanoparticles in organic solvent; (C) Phase transfer to a water-based solution, in two steps or in a one-step phase transfer and functionalization (red arrow); (D) Functionalization of the nanoparticles for selective and/or multifunctional imaging; (E) Imaging of atherosclerotic plaque with iron oxide nanoparticles. EPR, enhanced permeability and retention.

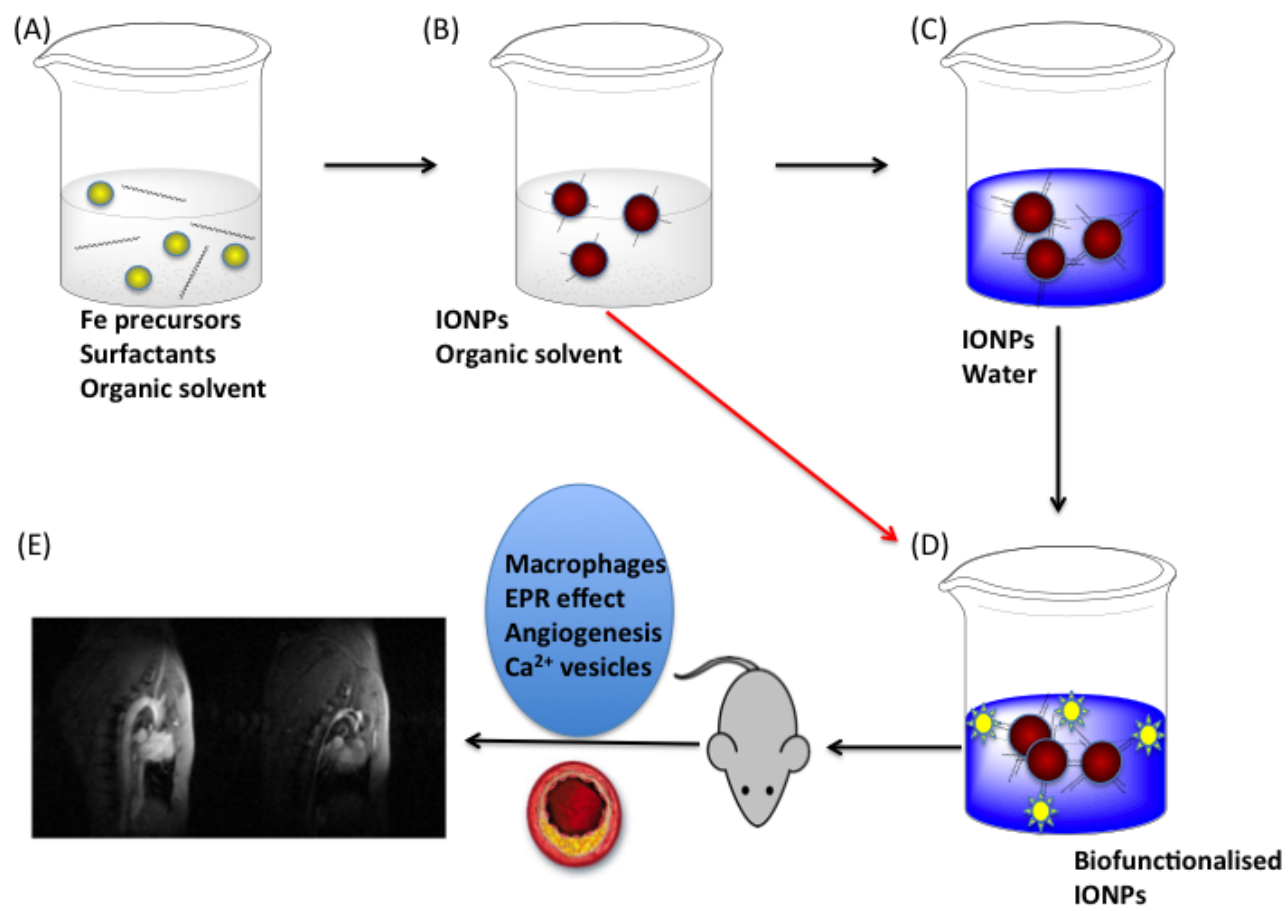

The interest in the application of these compounds in cardiovascular imaging and chemical probes, in general, is reflected in the number of reviews dealing with several aspects of the field. Our approach in this review is somehow different, and it is depicted in Figure 1. We will study the different steps allowing for the in vivo detection of atherosclerotic plaque. The first step is the combination of iron 
precursors and surfactants, which includes the selection of the most appropriate combination of compounds and solvent to get nanoparticles with good crystallinity, magnetic and colloidal properties. Next in this process is to get water-stable and functionalized nanoparticles. This has been traditionally done in two steps, a phase transfer reaction and a second step with the attachment of the biomolecule. However, with the development of new approaches that perform chemical reactions over the initial organic surfactant, this process can be reduced to a single step in which the stabilization in water and the attachment of a biologically relevant molecule is done altogether. The final step is the preclinical application of the nanoparticles to an animal model of atherosclerosis. To get the selective accumulation of the nanoparticles inside the body, several strategies can be followed, e.g., macrophage targeting, plaque calcification, the angiogenesis process or by taking advantage of the enhanced permeability and retention (EPR) effect [9].

By studying the different chemical routes for the synthesis of homogeneous superparamagnetic and biofunctionalized IONPs and the biology behind atherosclerosis disease, a rational and focused strategy can be developed for the synthesis of clinically-relevant nanoparticles.

\section{Synthesis of Iron Oxide Superparamagnetic Nanoparticles}

Due to the relevance and wide spectrum of applications with IONPs, there has been a tremendous increase in the synthetic methodologies in the past few years. The most relevant approaches include methods, such as coprecipitation [10-12], thermal decomposition [13-15], sonolysis [16,17], sol-gel processes [18,19], spray and laser pyrolysis [20-22], hydrothermal and high temperature synthesis [23-26], nanoreactors, such as protein cages [27-29], vesicles [30], microemulsions [31,32] and microwave-assisted synthesis [33-38]. For the sake of simplicity, we will focus here only on the most interesting ones from the biomedical point of view, particularly the most common ones with a higher prevalence and projection: coprecipitation, thermal decomposition and microwave-assisted synthesis.

\subsection{Co-Precipitation Method}

One of the most employed methodologies for the synthesis of iron oxide nanoparticles for biomedical applications is the co-precipitation method. This process involves a reaction of the aqueous mixture of $\mathrm{Fe}^{2+} / \mathrm{Fe}^{3+}$ salt solutions with a base. Under these conditions, magnetite nanoparticles are formed by the aggregation of primary particles within a $\mathrm{Fe}(\mathrm{OH})_{2}$ gel. This methodology, developed by Massart et al., was carried out initially without the incorporation of any stabilizing molecule on the surface of the nanoparticles.[10] In this work, they reported the controlled preparation of IONPs through alkaline precipitation of $\mathrm{FeCl}_{3}$ and $\mathrm{FeCl}_{2}$. The magnetite $\left(\mathrm{Fe}_{3} \mathrm{O}_{4}\right)$ particles formed were roughly spherical, with a diameter of $8 \mathrm{~nm}$, measured by XRD.

In this approach, magnetite is prepared by adding a base to an aqueous mixture of $\mathrm{Fe}^{2+}$ and $\mathrm{Fe}^{3+}$ salts in a 1:2 molar ratio. The overall reaction may be written as follows, leading to the precipitation of black magnetite [10]:

$$
\mathrm{Fe}^{2+}+2 \mathrm{Fe}^{3+}+8 \mathrm{OH}^{-} \rightarrow \mathrm{Fe}_{3} \mathrm{O}_{4}+4 \mathrm{H}_{2} \mathrm{O}
$$


In this reaction, a complete precipitation of $\mathrm{Fe}_{3} \mathrm{O}_{4}$ should be expected at $\mathrm{pH}$ 9, while maintaining a molar ratio of $\mathrm{Fe}^{3+}: \mathrm{Fe}^{2+}$ of $2: 1$. The reaction is performed under a non-oxidizing oxygen-free environment, by bubbling $\mathrm{N}_{2}$ in the reaction, something that also helps to reduce the final size of the nanoparticles [39].

A wide variety of parameters must be considered in this method in order to control size, magnetic characteristics and colloidal stability in the solution. Magnetization can vary drastically with synthesis variations even within particles of a similar size, due to the incorporation of impurities into the crystal structure and the involvement of surface effects [40,41]. Generally, magnetization saturation values of magnetite nanoparticles obtained by this method are in the range of 30-50 emu/g; lower than the $90 \mathrm{emu} / \mathrm{g}$ reported for their bulk form [42,43]. In addition, the determining parameter in controlling their size is the $\mathrm{pH}$, which must be adjusted in both the synthesis and purification steps. As a result, the production of narrowly dispersed particles remains a significant challenge in this method [44]. Other factors, like adjustment of the $\mathrm{Fe}^{3+}: \mathrm{Fe}^{2+}$ ratios, heating regimes and the coating-iron ratios must be strictly controlled $[45,46]$.

After the initial development by Massart et al., the number of coatings that have been used vary from polymers [47-50], to dendrimers [51] and organic acids [52-54]. For example, adding increasing amounts of citrate ions in the Massart process allows for a decrease in the diameter of citrate-coated nanoparticles from 8 to $3 \mathrm{~nm}$. Citrate chelates iron ions, preventing nucleation, and at the same time, the adsorption of citrate on the nuclei produces hydrolysis, inhibiting the growth of the nuclei [55].

The main advantage of the co-precipitation process is that a large amount of water-stable nanoparticles are obtained. However, the control of particle size distribution is limited, because only kinetic factors are controlling the growth of the crystal. This leads to the synthesis of somehow heterogeneous samples in terms of size and shape. Another problem that can be found with this approach is the weak attachment of the surfactant to the surface and the reduced number of functional groups that can be found on the surface, all of this complicating the final functionalization for biomedical applications.

\subsection{Thermal Decomposition of Organic Precursors}

High temperature decomposition of iron organic precursor mixed with surfactants in organic solvents is progressively becoming the standard way for the preparation of IONPs. This method yields nanoparticles of a narrow size distribution, good crystallinity and high magnetization saturation values (Figure 2) [56]. The first synthesis introduced by Aliviastos et al. reported the injection of $\mathrm{FeCup}_{3}$ (Cup: $N$-nitrosophenylhydroxylamine) solutions in hot trioctylamine resulting in nanoparticles of 4 to $10 \mathrm{~nm}$ average diameters as a function of the temperature $\left(250{ }^{\circ} \mathrm{C}\right.$ to $\left.300{ }^{\circ} \mathrm{C}\right)$ and the quantity of iron precursor added. A second method consisted of the preparation of iron nanoparticles by the injection of the organic $\mathrm{Fe}(\mathrm{CO})_{5}$ precursor in the surfactant mixture followed by an in situ oxidation phase to produce highly crystalline and monodispersed maghemite nanoparticles with sizes from 4 to $16 \mathrm{~nm}$ [57-59]. Although the hot injection technique guarantees instant nucleation and homogenous growth for an optimal quality of the nanoparticles, it also presents drawbacks mainly related to safety and toxicological issues [60]. Heating up processes were then proposed with iron oleate, an intermediate prepared from $\mathrm{FeCl}_{3}$ and the mechanisms of crystallizations studied [61,62]. In 2002, 
Sun et al. described a single step synthesis using iron acetylacetonate thermal degradation by progressive heating in diphenyl ether in the presence of alcohol, oleylamine and oleic acid surfactants $[13,63]$. The magnetite nanoparticles prepared with this method have dimensions in the 3 to $20 \mathrm{~nm}$ range adjusted by a control of the reaction time or the amount of the low complexing reactants. $\mathrm{FeO}(\mathrm{OH})$ has also been proposed as an organic precursor for thermal synthesis to produce nanoparticles with sizes below $20 \mathrm{~nm}$ [64]. A summary of the most relevant approaches using the thermal decomposition of organic precursors can be found in Table 1.

Figure 2. TEM images of 16-nm IONPs synthesized by the decomposition of organic precursors: (A) a monolayer assembly; (B) a multilayer assembly; (C) High Resolution Transmission Electron Microscopy (HRTEM) image of a single $\mathrm{Fe}_{3} \mathrm{O}_{4}$ nanoparticle. Reproduced with permission from [13]. Copyright 2002, American Chemical Society.

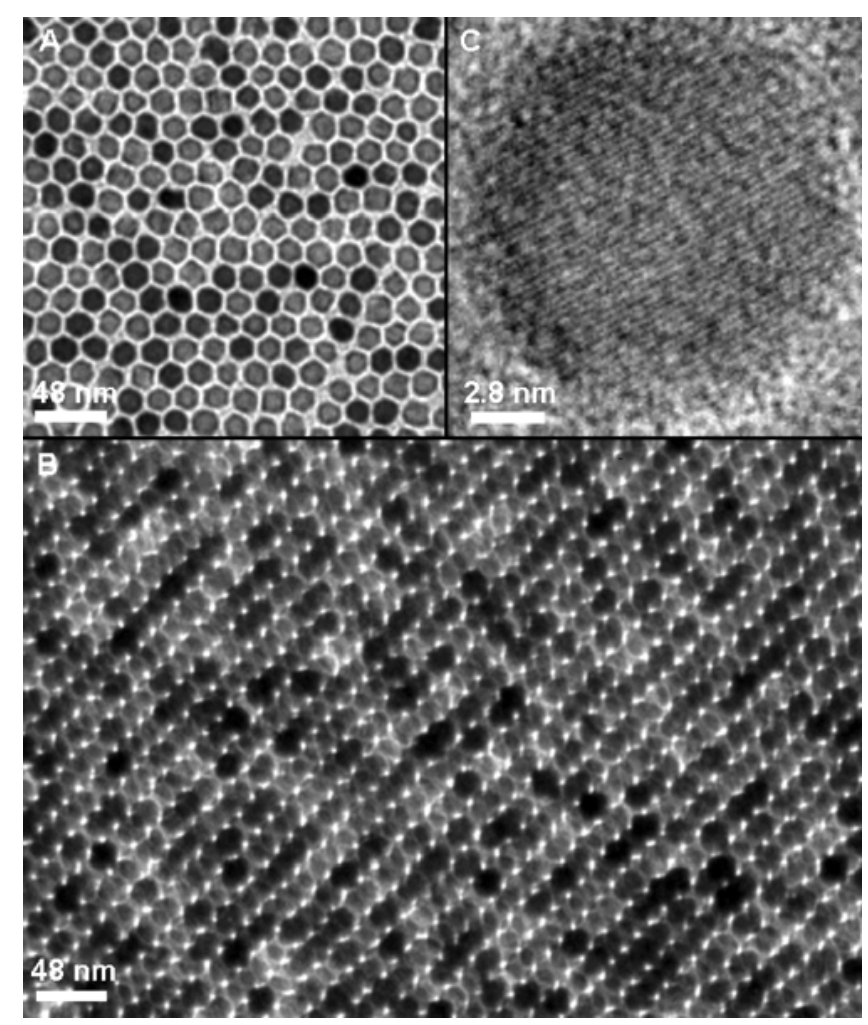


Table 1. Main aspects of the synthesis of superparamagnetic iron oxide nanoparticles by thermal decomposition methods. PAA, polyacrylic acid.

\begin{tabular}{|c|c|c|c|c|c|}
\hline Iron precursors & Surfactant & Solvent & $\mathbf{T} /{ }^{\circ} \mathbf{C}$ & Shape and Size & Refs. \\
\hline $\mathrm{FeCup}_{3}$ & Octylamine & Trioctylamine & $250-300^{\circ} \mathrm{C}$ & $4-10 \mathrm{~nm}$ & {$[15]$} \\
\hline $\mathrm{Fe}(\mathrm{CO})_{5}$ & Oleic acid & Dioctyl ether & $300^{\circ} \mathrm{C}$ & $4-16 \mathrm{~nm}$ & [57] \\
\hline $\mathrm{Fe}(\mathrm{CO})_{5}$ & $\begin{array}{l}\text { tri-n-octylphosphine } \\
\text { oxide (TOPO) }\end{array}$ & Ortho-dichlorobenzene & $180^{\circ} \mathrm{C}$ & $\begin{array}{l}12 \mathrm{~nm} \text { variation possible } \\
\text { (diamond, triangle, spherical) }\end{array}$ & [67] \\
\hline $\mathrm{Fe}(\mathrm{acac})_{3}$ & $\begin{array}{l}\text { Oleic acid } \\
\text { Oleyl amine }\end{array}$ & $\begin{array}{l}\text { Phenyl ether } \\
\text { or benzyl ether }\end{array}$ & $259-298{ }^{\circ} \mathrm{C}$ & $\begin{array}{l}<20 \mathrm{~nm} \\
\text { Seed mediated growth: } 20 \mathrm{~nm}\end{array}$ & $\begin{array}{l}{[13]} \\
{[63]}\end{array}$ \\
\hline $\begin{array}{l}\mathrm{Fe}(\text { oleate })_{3} \text { from } \mathrm{FeCl}_{3} \\
\text { and sodium oleate }\end{array}$ & Oleic acid & $\begin{array}{l}\text { 1hexadecane or } \\
\text { trioctylamine or ( } 2 \text { more })\end{array}$ & $274-365^{\circ} \mathrm{C}$ & $5-22 \mathrm{~nm}$ & [61] \\
\hline $\mathrm{FeO}(\mathrm{OH})$ & Oleic acid & 1-octadecene & $320^{\circ} \mathrm{C}$ & $6-30 \mathrm{~nm}$ & [64] \\
\hline $\mathrm{Fe}(\mathrm{acac})_{3}$ & 2-pyrrolidone & 2-pyrrolidone & $245^{\circ} \mathrm{C}$ & $5 \mathrm{~nm}$ & [14] \\
\hline $\mathrm{FeCl}_{3}$ & 2-pyrrolidone & 2-pyrrolidone & & Seed mediated growth: $11 \mathrm{~nm}$ & [13] \\
\hline \multirow[t]{2}{*}{$\mathrm{Fe}(\mathrm{acac})_{3}$} & m PEG-COOH & 2-pyrrolidone & $240^{\circ} \mathrm{C}$ & $12-30 \mathrm{~nm}$ & [71] \\
\hline & d PEG-COOH & 2-pyrrolidone & $240{ }^{\circ} \mathrm{C}$ & & [72] \\
\hline $\mathrm{Fe}(\mathrm{acac})_{3}$ & PVP & $\mathrm{N}$-vinyl-2-pyrrolidone & $200^{\circ} \mathrm{C}$ & $4-40 \mathrm{~nm}$ & [73] \\
\hline $\mathrm{FeCl}_{3}$ & PAA & diethylenglycol & $220^{\circ} \mathrm{C}$ & $3-12 \mathrm{~nm}$ & [74] \\
\hline
\end{tabular}

The size and morphology of the nanoparticles are the result of the growth mechanism during the thermal decomposition method. We will focus in this review only on the influence of the different reaction conditions; further details of the growth mechanism models have been reviewed in several occasions, like in Gao et al [65]. For instance, the time of reaction of the growth phase clearly regulates the size [66]. Furthermore, nanoparticles prepared with higher temperatures lead to larger sizes; successfully employed by heating with various solvents of high boiling points [61]. Another critical variable in the structural features of the nanoparticles is the surfactant or mixture used for emulsifying the systems and to control nucleation. It was observed that the size of the nanoparticles is inversely proportional to the tendency of the surfactant to coordinate with the iron atom [67,68]. Thus, common methods often control the size of the nanoparticles by the addition of a low complexing surfactant [68]. Sizes can also be modified depending on the molar proportion, Fe:surfactant [64]. Finally, it was shown that the affinity properties of the solvent for iron can play a major role in this process [69]. Although few studies also assessed the influence of the organic iron precursors, preliminary observations show that a narrower and controlled particle size distribution is favored with a specific iron intermediate complex before the generation of the cores [70]. 
Shape-controlled synthesis of iron oxide nanoparticles with this method can be performed under thermodynamic or kinetic control. Thermodynamic control is the key aspect when working with a low concentration of precursors, yielding spherical nanoparticles to minimize the surface energy. When working at high concentration conditions, kinetic control will lead to the formation of particles with other morphologies, such as cubic or elongated particles [62,69,75].

The above described thermal decomposition synthesis is a powerful method to produce IONPs of higher quality than the ones prepared by the aqueous routes [68]. One drawback of this approach is that the hydrophobic character of the nanoparticles makes compulsory a second step to transfer the IONPs to water. This necessity of rendering hydrophilic nanomaterials has boosted the appearance of new efficient chemical routes for the functionalization of nanoparticles.

Before the use of these new alternatives, the efforts focused on the modification of the thermal decomposition method with hydrophilic surfactants and/or polar solvents to provide hydrophilic nanoparticles in a one-pot synthesis route. Gao's group first reported the use of 2-pyrrolidone, a strong polar organic solvent [14]. In the first attempt, 2-pyrrolidone had also the role of surfactant with $\mathrm{Fe}(\mathrm{acac})_{3}$ as the iron precursor. These nanoparticles of roughly $5 \mathrm{~nm}$ were hydrophilic, but with poor stability, being stable under acidic or alkaline conditions, which provides optimum electrostatic repulsion, but showed aggregation at neutral $\mathrm{pH}$ conditions. This method was assessed also with $\mathrm{FeCl}_{3} \cdot 6 \mathrm{H}_{2} \mathrm{O}$ as a precursor to obtain nanoparticles with an average size between $4 \mathrm{~nm}$ and $60 \mathrm{~nm}$ [76]. In order to synthesize nanoparticles stable in physiological solutions, mono- or di-carboxylicterminated poly(ethylene glycol) (PEG) polymers were introduced as the surfactant [71,72]. The amphiphilic character of this PEG coating confers on iron oxide nanoparticles' important properties, such as high stability and solubility in different media [14]. Moreover, di-substituted carboxylic polymers have the advantage of showing a reactive group on the surface for further functionalization. These results opened a range of new studies assessing others polar organic solvents and surfactants, such as polyacrylic acid (PAA), $N$-vinyl-2-pyrrolidone, glycols or diphenyl oxide [73,74,77,78].

\subsection{Microwave-Assisted Synthesis}

The use of microwaves in inorganic chemistry goes back to the 1970 s and in organic chemistry to the 1980s. Although slow at the initial stages, the utilization of microwaves in chemical synthesis processes boosted from the mid-1990s. The main reasons for this increase included the availability of commercial equipment, the short reaction times and the expanded reaction range that is offered by microwave-assisted synthesis. These features make this approach particularly suited for the increased demands in industry.

In general, most of the synthetic reactions to obtain IONPs include heating through traditional heat transfer equipment, such as oil baths, sand baths and heating jackets. These heating techniques are, however, rather slow, and a temperature gradient can develop within the sample, leading to local overheating spots. All these parameters may have an important effect both in the nucleation and growing steps of the synthesis. A fundamental aspect of the microwave approach is the dielectric heating; under these conditions, the energy is introduced into the reactor remotely. The microwave radiation passes through the walls of the vessel and heats only the reactants and solvent and not the reaction vessel itself. In modern pressurized equipment, the temperature increase is uniform 
throughout the sample and facilitates heating far above the conventional boiling point of the solvent. All these features allow for the synthesis of IONPs with greater control/reproducibility of size and dispersity, as well as enhanced crystallinity.

The characteristics we just highlighted are attracting the attention of many scientists working in the synthesis of nanoparticles. Currently, there are examples in the literature of the use of microwaves for the synthesis of maghemite nanoparticles [33-35], mixed maghemite and magnetite nanoparticles [36] and pure magnetite [38]. Due to the novelty of the approach, most of the recent publications focused more on the synthesis of the nanoparticle core and rather poorly on the colloidal stability of the synthesized nanoparticles in water. This is gradually changing, and there are examples already using PEG and dextran as surfactants for biomedical applications [24,79,80]. Considering these data, it is not difficult to foresee in the near future a field where the utilization of microwaves for the synthesis of IONPs will be of paramount importance; for example, in the synthesis of dual PET/MRI nanoparticles, where not only the quality of the nanoparticles is important, but also the rapid incorporation of the radioisotope, particularly with those of reduced half-life isotopes $\left({ }^{18} \mathrm{~F}\right.$ and $\left.{ }^{68} \mathrm{Ga}\right)$ [81]. The synthesis of this type of nanoparticles would be a clear improvement in comparison with traditional chelator-based compounds from the point of view of toxicity, no transmetallation in vivo and a much better biodistribution, provided the surface of the nanoparticles is properly functionalized [82].

\section{Biofunctionalization of Iron Oxide Nanoparticles}

When developing nanoparticles for biomedical or cardiovascular applications, the key point is the functionalization of the nanoparticles' surface. Ideally, the functionalization should provide nanoparticles with very good colloidal stability in the usual conditions for in vivo administration (i.e., $0.9 \% \mathrm{NaCl}$, PBS, etc.) and provide as many as possible functional groups that can be employed for the attachment of biomolecules.

The approach is different depending on the hydrophilic character of the initial IONPs. For those obtained by the coprecipitation method, the next step after the synthesis is the attachment of the biomolecule of interest. This sometimes can be a problem, since the number of functional groups on the surface is not that high. Since the IONPs obtained by thermal decomposition are usually of superior quality, we will focus this section on the functionalization of these particles.

Traditionally, for the stabilization of the hydrophobic nanoparticles synthesized by thermal decomposition, there were two main approaches: the micelle-like approach and the ligand exchange. Recently, a new approach has been developed by our group based on the direct chemical modification of the organic surfactant; something that presents a number of advantages [83-86].

\subsection{Ligand Exchange}

The ligand exchange approach is based on a mixture of hydrophobic IONPs with a very high concentration of the hydrophilic molecule. In such conditions, the hydrophilic ligand eventually displaces the hydrophobic surfactant, due to its affinity towards IONPs surface, thus yielding aqueous stable nanoparticles $[87,88]$. The most remarkable aspects of this approach are the simplicity and versatility, due to the enormous number of hydrophilic ligands that can be used for this purpose, like carboxylates, phosphates, polymers and inorganic materials (Table 2) [89-94]. However, this approach 
also presents some disadvantages. One of them is the degree of exchange. If this is not high, the surface of the nanoparticle will contain hydrophobic moieties, leading to stabilization problems and, most importantly, to a significant reduction in the number of reactive functional groups for further functionalization [95].

Table 2. Summary of the main properties for the most common ligand-exchange protocols.

DMSA, dimercaptosuccinic acid; PAMAM, poly(amido)amine; PAH, poly(allylamine).

\begin{tabular}{lcccc}
\hline Ligand & TEM $(\mathbf{n m})$ & DLS $^{\mathbf{1}}(\mathbf{n m})$ & $\boldsymbol{r}_{\mathbf{2}}\left(\mathbf{m M}^{\mathbf{- 1}} \mathbf{s}^{\mathbf{- 1}}\right)$ & Ref. \\
\hline DMSA & $9.0 \pm 2.0$ & $65.0 \pm 5.0$ & 317 & {$[103]$} \\
Citric acid & $4.0 \pm 0.5$ & $8.6 \pm 1.0$ & 33 & {$[56]$} \\
1-mercapto-11-undecanoic acid & $10.0 \pm 3.0$ & $170.0 \pm 50.0$ & n.a. & {$[104]$} \\
2-bromo-2-methylpropionic acid & $8.0 \pm 1.0$ & n.a. & n.a. & {$[105]$} \\
PEG-SiMe3 & $8.4 \pm 1.5$ & $12.2 \pm 2.7$ & n.a. & {$[98]$} \\
NH2-SiMe3 & $8.7 \pm 1.3$ & $14.4 \pm 2.8$ & n.a. & {$[98]$} \\
COOH-SiMe3 & $8.2 \pm 1.2$ & $13.5 \pm 2.0$ & n.a. & {$[98]$} \\
Hydroxyethylenebisphosphonate & $5.0 \pm 1.5$ & $15.2 \pm 2.5$ & 122 & {$[101]$} \\
Stilbenephosphonate & $6.0 \pm 0.5$ & $39.0 \pm 5.0$ & n.a. & {$[106]$} \\
PMIDA ${ }^{2}$ & $5.0 \pm 0.5$ & $62.0 \pm 3.0$ & n.a. & {$[107]$} \\
PAMAM & $5.0 \pm 2.0$ & $90.0 \pm 20.0$ & 79 & {$[108]$} \\
Melanin-Dopamine & $10.0 \pm 2.0$ & n.a. & 114 & {$[109]$} \\
PAA-PAH & $11.0 \pm 2.0$ & $60.0 \pm 10.0$ & n.a. & {$[110]$} \\
PNIPAM-b-PNIPAM ${ }^{3}$ & $15.0 \pm 3.0$ & $60.0 \pm 4.0$ & n.a. & {$[111]$} \\
DPA ${ }^{4}$-PEG-COOH & $9.0 \pm 1.0$ & $40.0 \pm 2.0$ & n.a. & {$[112]$} \\
\hline${ }^{1}$ DLS: Dynamic $\quad$ Light Scattering; ${ }^{2}$ PMIDA: & $N$-phosphonomethyl & iminodiacetic & acid; \\
${ }^{3}$ PNIPAM: Poly $N$-isopropylacrylamide); ${ }^{4}$ DPA: methacrylate-co-2-(diisopropylamino)ethyl methacrylate.
\end{tabular}

In general, the ligands utilized in this approach can be classified as small organic molecules and large polymeric compounds, such as dimercaptosuccinic acid (DMSA). This ligand, due to the carboxylic groups, shows a high affinity towards the IONP surface, thus providing high stability in aqueous media and enough free functional groups for further biomolecule conjugation with many applications [77,96,97]. DMSA-nanoparticles, with a small hydrodynamic size (less than $50 \mathrm{~nm}$ ) and very good magnetic properties, can be obtained with this approach. These nanoparticles can be employed, for instance, for MRI and also drug delivery. Citric acid is another carboxylic-based ligand for the ligand exchange approach of common use in this very field. This acid may be adsorbed on the surface of the magnetite nanoparticles via one of the two carboxylate groups, depending on steric hindrance and the curvature of the surface. This leaves at least one of these functional groups exposed to the solvent, which should be responsible for making the surface negatively charged and hydrophilic [56].

Another kind of ligand with good properties for the exchange approach are silanes (Figure 3). These compounds present the general chemical formula, $\mathrm{X}-\left(\mathrm{CH}_{2}\right)_{\mathrm{n}}-\mathrm{SiR}_{3}$, where $\mathrm{SiR}_{3}$ is the anchor group having good affinity for the surface of the nanoparticle, $\left(\mathrm{CH}_{2}\right)_{\mathrm{n}}$ is the hydrophobic chain and $\mathrm{X}$ is the headgroup providing the hydrophilicity. Further surface modifications are possible depending on the $\mathrm{X}$ group [98]. The efficiency of ligand exchange reactions with silanes depends on various factors, like the concentration of the silicon tetrahydride, the reaction times and the presence of a catalyst [99]. 
Although ligand exchange is a straightforward method and these factors can be easily controlled, the method with silanes shows poor reproducibility [100]. Other small molecules that have been used in this approach are phosphonates, of several compositions [101,102].

The utilization of large polymeric compounds for the exchange approach includes dendrimers, polyacrylic acid and PEG. In the case of dendrimers, the most common of these molecules in biomedicine, poly(amido)amine (PAMAM), is also the most commonly used for the functionalization of IONPs. These dendrimers have been conjugated with targeting ligands, imaging moieties and drug molecules for its application in cancer therapy [108,113,114]. Moreover, poly(amido)amine IONPs are a suitable platform for further functionalization to increase the circulation time of the nanoparticles in blood [51]. These macromolecules are obtained via conventional organic synthesis. In this regard, maghemite nanoparticles with uniform and monodisperse sizes were functionalized with dopamine, showing good aqueous stabilization [109].

Figure 3. Structure of common silane-based molecules for the ligand exchange approach.<smiles>CCO[Si](CCCN)(OCC)OCC</smiles>

Amino<smiles>CCO[Si](CC)(OCC)OCC</smiles>

Aldehyde<smiles>C=CC(=O)OCCC[Si](OCC)(OCC)OCC</smiles>

Acrylate<smiles>CCO[Si](CCCN(CCN(CC(=O)[O-])CC(=O)[O-])CC(=O)[O-])(OCC)OCC</smiles>

Carboxylate<smiles>CCO[Si](CCCCCCCCCC#N)(OCC)OCC</smiles>

Cyano

EtO<smiles>CCO[Si](CCCN=C=O)(OCC)OCC</smiles>

Isocyanate<smiles>CCO[Si](CC(C)(C)COC)(OCC)OCC</smiles>

Polyethylenglycol<smiles>CCO[Si](CCCS)(OCC)OCC</smiles>

Thiol

Polyelectrolytes, such as poly(acrylic acid) (PAA) and poly(allylamine) (PAH), are employed to replace the original hydrophobic ligands on the surface of iron oxide nanoparticles. These polymers need high temperature in ligand exchange reactions with IONPs. Therefore, polar solvents with a high boiling point, like diethylene glycol, are commonly used. Moreover, diethylene glycol has high miscibility in both aqueous and typical organic solvents and high power to dissolve polyelectrolytes, providing good features for this type of ligand exchange reaction with polymers at high temperature $\left(>240^{\circ} \mathrm{C}\right)$. In the case of PAA-PAH, nanoparticles, with a narrow core size distribution, stability in water and good magnetic properties, are obtained in a short reaction time [110].

As we have mentioned before, nanoparticle PEGylation with chains of different molecular weight, is well established to optimize the stabilization of nanoparticles and to prolong their circulation time in 
blood after administration [115-117]. Regarding the utilization of this polymer in the ligand exchange approach, one of the best examples is the use of DPA-PEG-COOH (DPA: methacrylate-co-2(diisopropylamino)ethyl methacrylate), a synthetic compound produced from polyethylene glycol diacid (HOOC-PEG-COOH), in which one of the acid groups reacts with the terminal free amine of dopamine through the conventional EDC/NHS (1-Ethyl-3-(3-dimethylaminopropyl)carbodiimide/ $N$ Hydroxysuccinimide) reaction obtaining DPA-PEG-COOH. After a ligand exchange reaction among DPA-PEG-COOH and oleic acid nanoparticles, water stable nanoparticles are achieved, even with different length chains of PEG. These nanoparticles have proven to have much less uptake by macrophages, indicating that these can evade recognition from these cells of the immune system [112].

\subsection{Micelle-Like Approach}

Figure 4. Micelle approach for PAMAM-C12 coating of the oleic acid-capped iron oxide nanoparticles. Reproduced with permission from [142]. Copyright 2013, American Chemical Society.

NP-OA
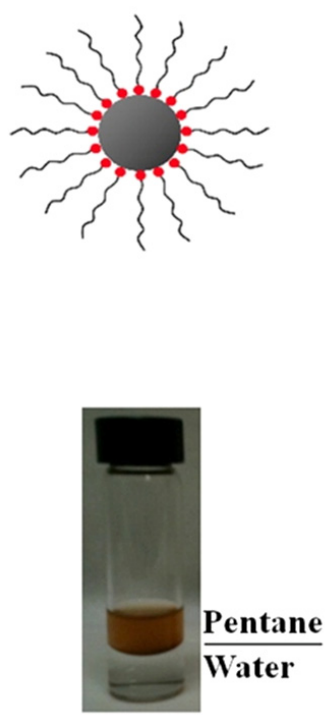

(A)
PAMAM-C 12
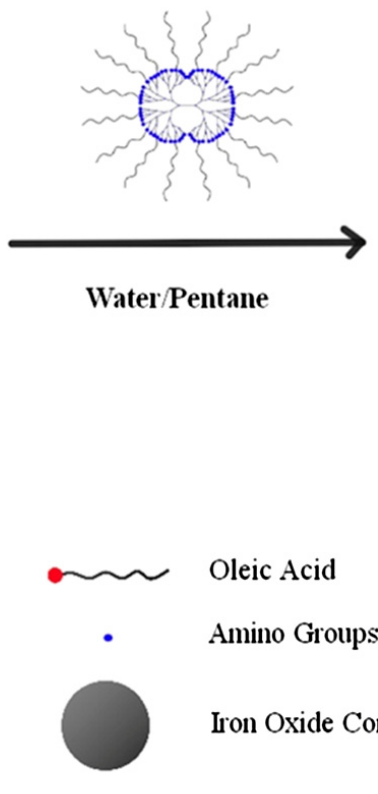

$\sim$
Oleic Acid

Amino Groups

Iron Oxide Core

Hydrophobic Chains
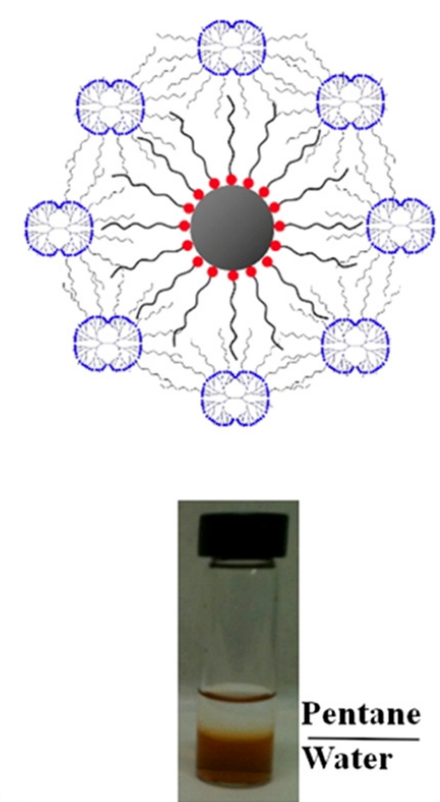

(B)

The utilization of amphiphilic structures for the stabilization and functionalization of IONPs is a second approach usually selected when synthesizing these compounds [118-122]. This method takes advantage of the structure of these amphiphilic molecules. The formation of weak van der Waals interactions between the hydrophobic part of these molecules and the organic tail of the nanoparticle coating, to minimize the interaction with water, produces very stable nanoparticles with excellent reproducibility (Figure 4). Furthermore, the possibility of a previous modification on the amphiphilic molecule allows for the stabilization and functionalization of the IONPs to be carried out in a single step, although this opportunity has not been fully addressed. To obtain such micelle-like structures, usually, the first option is to use a polymeric amphiphilic compound. The hydrophobic structure is 
inserted between the hydrophobic chains of the surfactant/ligand adsorbed on the nanoparticle, while the hydrophilic part stands around the outer surface to assure the dispersion of the IONPs in biological media. Many kinds of polymers have been assessed, like pluronic [123-126], poly(maleic anhydride alt-1-tetradecene) [127], cyclodextrins [128], PEG-phospholipids conjugates [129,130] or other triblock polymers [131-133]. Other advantages of the method are the possibility of further crosslinking for better stabilization or encapsulation of small hydrophobic drugs in the hydrophobic bilayer that is created (as well as small organic fluorescent molecules). The final stability of the structure depends mainly on the nature of the polymers, i.e., amphiphilic balance, molecular weight, length of the chains or conformation [131].

To achieve the insertion of the polymers, several methods are possible, such as reverse evaporation [134,135], progressive increase of the solvent polarity [131] or nanoemulsion [136]. The encapsulation of hydrophobic nanoparticles in polymeric micelles [137] is very similar to the insertion option. Many examples are in the bibliography using diblock polymers, such as polylactide-bpoly(ethylene-maleimide) [122,138], poly(styrene-block-acrylic acid) [131], poly(e-caprolactone)-bpoly(ethylene glycol) $[139,140]$ or dendrimers [141].

Control of self-assembly structures can be achieved from micelles to vesicles, based on the nature of the solvent used and other conditions [133]. Liposomes are another important structures based on amphiphilic compounds. Liposomes are vesicles composed of a lipid bilayer, and a very important platform for drug delivery and imaging applications [143]. To explain in detail the utilization of liposomes in general or their application in the synthesis of iron oxide nanoparticles, one will need another review, so we refer the reader to other sources already dealing with this aspect in detail, particularly those by Torchilin et al. in 2005 and Alen et al. in 2013 [142-147]. Here, we will only mention one work, especially relevant for the topic covered in this review, by Fayad and Mulder et al. (Figure 5) [148]. In this work, an HDL-like nanoparticle (HDL, high density lipoprotein) was developed with multimodal imaging properties, by including additional labels in the corona of the particles, such as iron oxide, Au and quantum dots. The in vitro and in vivo characterization of these particles demonstrated that they mimic many of the properties of the native HDL and, therefore, could be used for in vivo imaging of atherosclerotic plaque.

Figure 5. Schematic structure and TEM imaging of HDL-iron oxide nanoparticles. Adapted with permission from [149]. Copyright 2008, American Chemical Society.
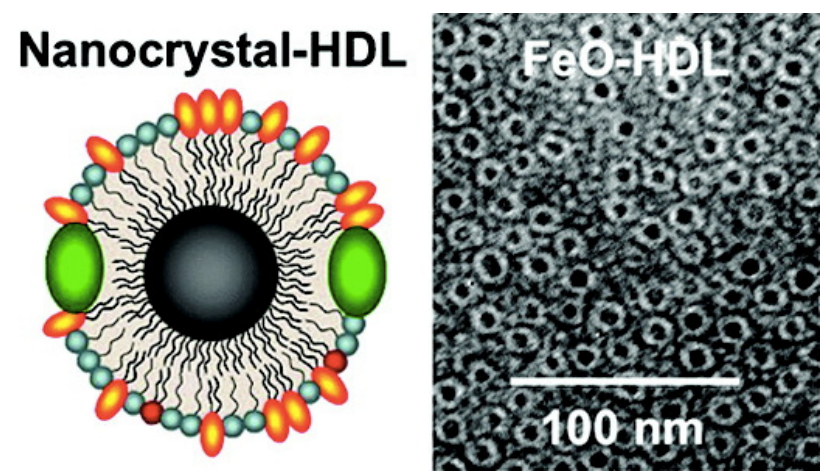


\subsection{Chemical Modification of the Surfactant}

One of the new approaches that we review is based on the direct chemical modification of the surfactant, usually oleic acid. The ligand exchange method is based on the partial replacement of the oleic acid, whilst the micelle approach focuses on keeping it, but hidden below at least under a layer of the amphiphilic molecules. The chemical modification approach is based instead on performing organic reactions over the oleic acid. The final intention of this method is to bring all organic chemistry tools for the synthesis and functionalization of hydrophilic molecules. Although different alternatives can be foreseen, the most logical one is to perform chemistry in the functional group of oleic acid that is not involved in the surface binding of the nanoparticles: the carbon-carbon double bond. So far, there are two strategies that have been followed in this approach (Figure 6).

Figure 6. Direct chemical modification of the surfactant for oleic acid-coated IONPs, by (A) oxidation of the double bond and (B) olefin metathesis by the use of Hoveyda-Grubbs 2nd generation catalyst.

(A)

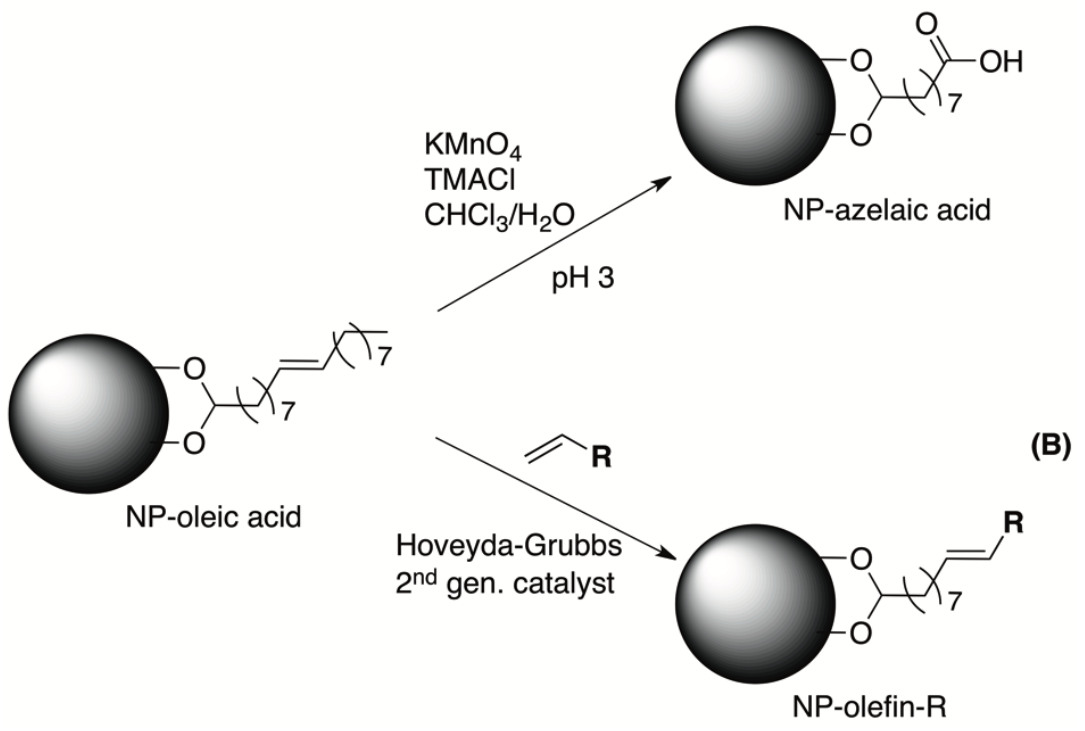

We have demonstrated this approach for the first time in iron oxide nanoparticles, by using the very well-known double-bond oxidation with $\mathrm{KMnO}_{4}$ to generate a carboxylic group (Figure 6A). It is known that under these conditions, the permanganate ion forms a complex with the double bond that can be hydrolyzed in both acidic and basic $\mathrm{pH}$. Under these conditions, IONPs were obtained with a $40 \mathrm{~nm}$ mean diameter, a zeta potential of $-46 \mathrm{mV}$ and good magnetic $(\mathrm{Ms}=77 \mathrm{emu} / \mathrm{g} \mathrm{Fe})$ and relaxometric properties ( $r_{1}$ and $r_{2}$ are $4 \mathrm{~s}^{-1} \mathrm{~mm}^{-1}$ and $115 \mathrm{~s}^{-1} \mathrm{~mm}^{-1}$ ). The reaction is performed in a two-phase system, a mixture of organic solvent, where the oleic acid nanoparticles are dispersed, and an aqueous phase, where the $\mathrm{KMnO}_{4}$ is soluble and where the IONPs are eventually dispersed. In this procedure, a phase-transfer catalyst is used to get enough concentration of the $\mathrm{MnO}_{4}^{-}$ion in the organic phase. The best results are obtained usually with trimethylbenzylammonium chloride.

This modification renders water-stable particles and, at the same time, also, a functional group ready for the further attachment of biomolecules, from small organic molecules to dyes and 
proteins $[84,85]$ (Figure 7). Two of the most remarkable features of these modifications are that the nanoparticle is always protected by a layer of surfactant, thus minimizing the aggregation and that, by using an excess of the oxidant, a complete transformation of the oleic acid is achieved, as we demonstrated using magnetic resonance spectroscopy, mass spectrometry and infrared. This is a very important difference compared to the previous methods. By removing all oleic acid from the surface, more stable nanoparticles and less toxicity problems are expected. The same is true for further functionalization, since this approach allows for strong covalent interaction that, at no point, exposes the core of the nanoparticle $[83,150]$.

Figure 7. Synthesis of multifunctional IONPs by the direct chemical modification of oleic acid. The attachment of allergen $\mathrm{Phl} \mathrm{p5a}$ and a fluorophore, via biotin-streptavidin interaction, was done by amide formation with the carboxylic groups generated. TEM image of the final IONPs (bottom left). Immunogenicity of the synthesized nanoparticles compared to non-functionalized particles, grass pollen extract and pure protein (bottom right). Reproduced from [87]. Copyright 2012, John Wiley \& Sons, Ltd.
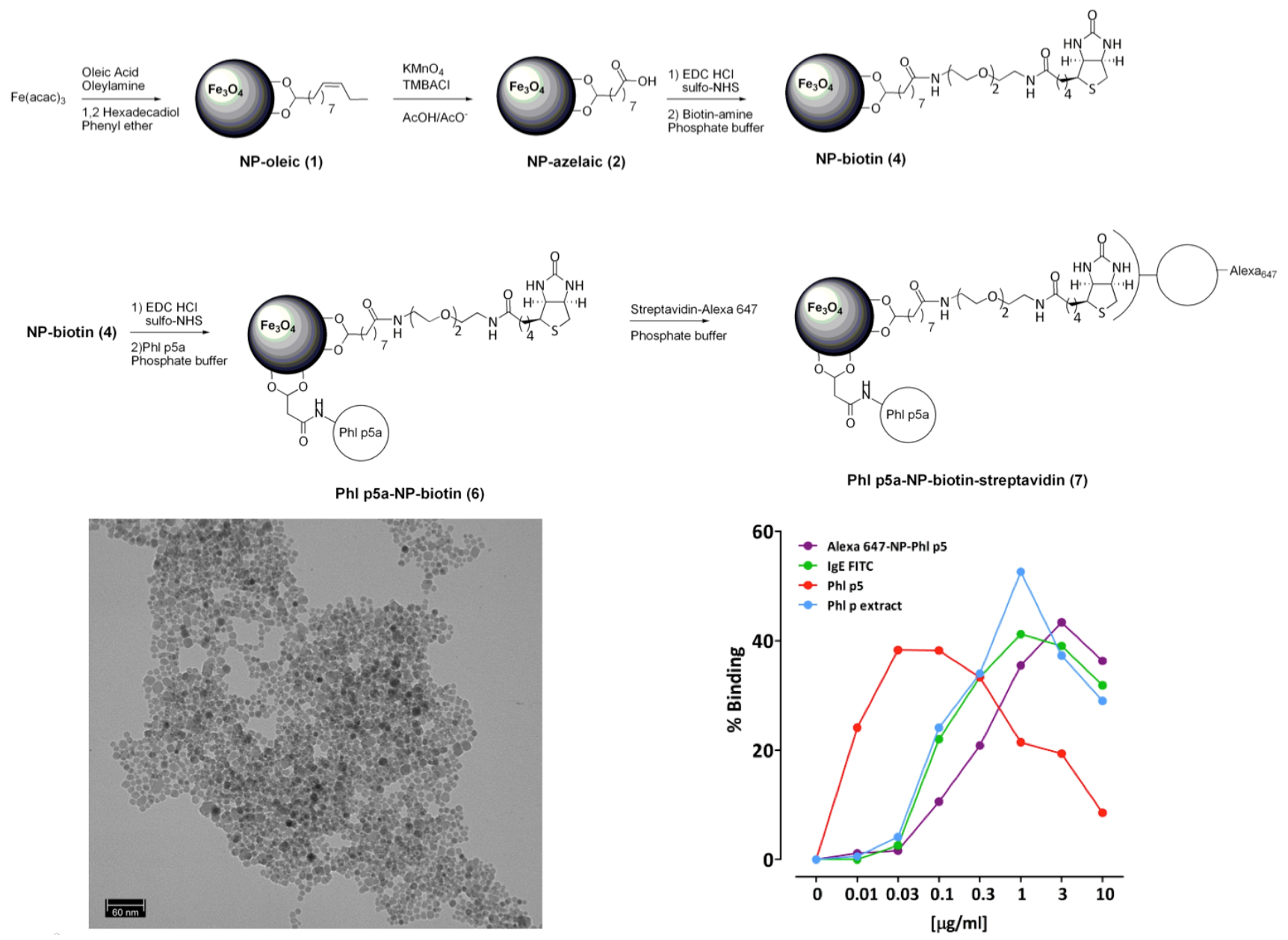

A second recent initiative is the direct modification of oleic acid using another well-known reaction in organic chemistry, the olefin cross-metathesis. The idea behind this is to take advantage of the functional group in the oleic acid. However, with the olefin metathesis option, we can go one step further. Since it is possible to incorporate a terminal olefin in many proteins and biomolecules, it can 
be utilized for, in a single step, transferring the nanoparticles to water and providing specificity for biomedical applications $[86,149,151]$. Using this method, biofunctionalized IONPs are obtained again in two steps, but with better physicochemical properties.

\section{Application to Atherosclerotic Plaque}

Atherosclerosis is an inflammatory pathology of the blood vessel wall in which plaque builds up inside the arteries [152-156]. Plaque is mainly made up of lipids, cholesterol, calcium, macrophages and several substances found in the blood. Over time, plaque hardens and narrows the arteries, limiting the flow of oxygen-rich blood to the organs.

During the atherothrombotic plaque formation, relevant events take place: inflammation, deposition of cholesterol, extracellular matrix (ECM) development and thrombosis [157-159]. Characteristics of atherosclerosis are the presence of fibrous and lipid-rich elements in vessel walls of arteries (coronary, carotid and aorta as the most common injured arteries). During the course of the pathology, myeloid cells de-stabilize the plaque, causing it to rupture [160]. Most of the damage occurs when plaques become fragile and rupture. Plaques that rupture cause the formation of blood clots that can block blood flow or break off and travel to another part of the body. Monocytes are infiltrated during early damage in the arterial wall and, in combination with macrophages, promote the inflammatory process. After activation of macrophages from monocytes in the sub-endothelial space, the ingestion of high amounts of lipids by the activated macrophages triggers the origin of foam cells. The accumulation of lipid cores by foam cells activated macrophages and necrotic cells, leading to the migration of smooth muscle cells to intima, forming the fibrous cap over the damage (Figure 8). These inflammatory events' expression, accompanied with the delivery of proteolytic enzymes (metalloproteinases, cysteinyl cathepsins), which catabolize the extracellular matrix of fibrous cap in plaques, are responsible for plaque instability [161]. When this fibrous cap becomes thin, the plaque vulnerability risk is increased [152]. The complete mechanism explaining plaque instability and proneness to rupture is unknown yet [156].

\subsection{Molecular Imaging in Atherosclerosis}

One of the main issues of an atherosclerotic lesion is that it develops slowly over decades, being finally identified at advanced states of the pathology [155]. One of the main goals in the utilization of molecular imaging in atherosclerosis is the possibility of early diagnosis, at a subclinical point $[162,163]$.

Current approaches in atherosclerotic plaque imaging are mainly based on molecular imaging approaches by the targeting of biomolecules involved in the lesion progression. Macrophages are one of the most utilized targets in molecular imaging, due to their role during inflammation $[152,156,163]$. However, there are important biochemical targets that are indicative of plaque development, such as metalloproteinases, LDL-oxidized, calcium vesicles or receptors involved in neoangiogenesis [152,155,156]. Molecules involved in plaque rupture, like metalloproteinases (MMPs) and cathepsins, are highly recommended as molecular imaging targets. 
Figure 8. Evolution of atherosclerosis disease and the main targets at each step, according to the American Heart Assocciation (AHA). Reproduced with permission from [158]. Copyright 2008, Nature Publishing Group.

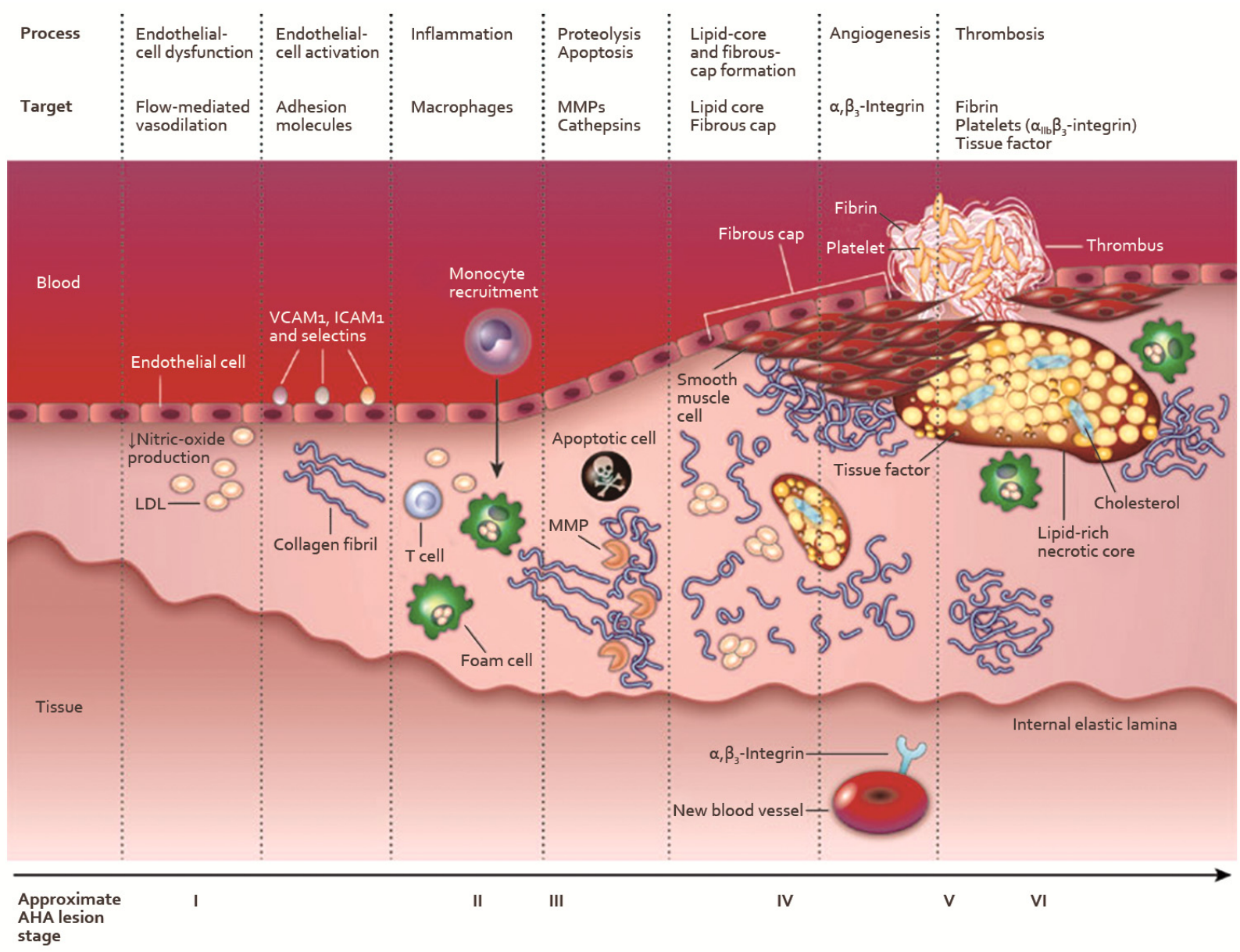

\subsection{Iron Oxide Nanoparticles in Atherosclerosis Imaging}

The use of IONPs for atherosclerosis targeting makes use of the principal markers of the disease, such as MMPs, angiogenesis, activated platelets, cell adhesion molecules, apoptosis markers and fibrin markers. The first results with IONPs as a platform for molecular imaging in this context comes from the rapid uptake by the macrophages of the immune system [164-168]. Systematic evaluation of MRI with IONP as a contrast agent in carotid atheroma confirmed that the optimal signal intensity was achieved 24-36 h after i.v. (Intravenous) administration. In 2000, it was demonstrated that there is a spontaneous phagocytic uptake of superparamagnetic iron oxide nanoparticles by macrophage populations in atherosclerotic plaque [164,169]. There are numerous examples showing the feasibility of atherosclerosis imaging by the non-specific labeling of macrophages [162,163,170]. This has been done, for example, in humans, with IONPs synthesized by the coprecipitation approach and coated with dextran [168]. This study showed that the nanoparticles accumulate predominantly in macrophages in ruptured and rupture-prone human atherosclerotic lesions, inducing significant signal changes in the in vivo $\mathrm{T} 2 *_{\mathrm{W}}$ fast gradient echo MRI. Similar results were obtained later, also in humans, with the same type of nanoparticles in the imaging of carotid atheroma. The nanoparticles accumulated in macrophages of seven out of eight patients, demonstrating areas of MRI signal 
reduction that correspond to IONPs/macrophage-positive histological sections. The MRI signal change was obtained between $24 \mathrm{~h}$ and $36 \mathrm{~h}$ after injection and was still evident up to $96 \mathrm{~h}$ after infusion. The explanation of how the IONPs are phagocytized by macrophages and end up in the plaque is related to the endothelial dysfunction theory. Plasma components are accumulated in the sub-endothelial space, allowing the progression of arterial wall inflammation. Low-density lipoproteins (LDL) are accumulated in their oxidized form and then phagocytized by macrophages. Finally, they form foam cells. The main similarity between LDL and IONPs are the diameter size (15-25 nm) and capability of accumulation in atheroma plaque with high macrophage activity [170]. Pharmacokinetics and the specific biodistribution of the probes based on IONPs depends on the particle size, as well as on the charge and surface properties $[152,156,170,171]$. Smaller particles are less efficiently uptaken than larger particles in the case of phagocytic cells.

Another important option for the use of IONPs in atherosclerosis is the binding of specific ligands on the surface of the particles to increase selectivity. This has been done also for the labeling of macrophages; for example, with the binding of the PP1 LSLERFLRCWSDAPAK peptide that binds to SR-A receptors. These belong to the scavenger receptor family, which has an important role during foam cell formation and consequent activation. Increased expression of these receptors has been reported in foam cells during atherosclerotic damage and vascular smooth muscle cells (VSMCs) after plaque inflammation events [163,172]. It is possible to conjugate this ligand to the IONPs in order to increase nanoparticle uptake. A significant increment of this PP1-conjugated IONPs in vitro using plaque-associated macrophages and VSMCs was reported [172]. Similar results of nanoparticle accumulations were obtained by contrast-based MRI in atherosclerotic plaque lesions with humanized models using Western-type diet-fed $\mathrm{LDLR}^{-/}$with human SR-AI, and in aged models with $\mathrm{ApoE}^{-/-}$mice [163].

Other important targets are cell adhesion molecules. Among them, due to its strict temporal and spatial expression/regulation, VCAM-1 has received most of the attention. There are several studies involving ligand-conjugated IONPs for MRI of endothelial adhesion molecules (VCAM-1 and P-selectin) [173,174]. IONPs have been conjugated with VCAM-1 internalizing peptides, identified by phage display. It has been reported that they are accumulated by cells with upregulated expression of VCAM-1, being specific for activated endothelium [153,156,173,174]. With the same aim of monitoring these proteins, IONPs could be also conjugated to specific moieties, like MHC-I peptides and VCAM-1 antibodies [156]. Another possible candidate is P-selectin, which is overexpressed on pathologically activated endothelium surfaces and activated platelets during atherosclerosis initiation, progression, rupture and thrombosis [175]. This marker has in fact been used for the synthesis of IONPs conjugated to an antihuman P-selectin antibody (VH10). The nanoparticles were validated in a model with $\mathrm{ApoE}^{-/-}$mice using a bimodal magnetofluorescent agent, for MRI and optical imaging of an inducible P-selectin expression in human activated platelets involved in the early stages of atherosclerosis [176]. Apoptosis is another event during plaque destabilization that has been used for the selective accumulation of IONPs in the atheroma lesion by the attachment of Annexin V in the surface of these nanoparticles. It is known that this protein has a high binding affinity for phosphatidylserine residues, translocated to the outer leaflet of the plasma membrane in apoptotic cells. The selective accumulation of such nanoparticles in atherosclerosis models in rabbits was shown by MRI [177]. 
Fibrin is also a good target for atherosclerosis detection with IONPs. Using a thermal decomposition approach, Sepan et al. prepared iron oxide nanoparticles coated with specific functional groups of fibrin by the nanoemulsion method (Figure 9), obtaining a micelle-like nanostructure. These nanoparticles were tested using T1 weighted imaging, which is far much easier to identify in vivo [178].

Figure 9. Fibrin-specific IONPs for the T1-weighted imaging of fibrin in atherosclerotic plaque. Reproduced with permission from [178]. Copyright 2009, American Chemical Society.

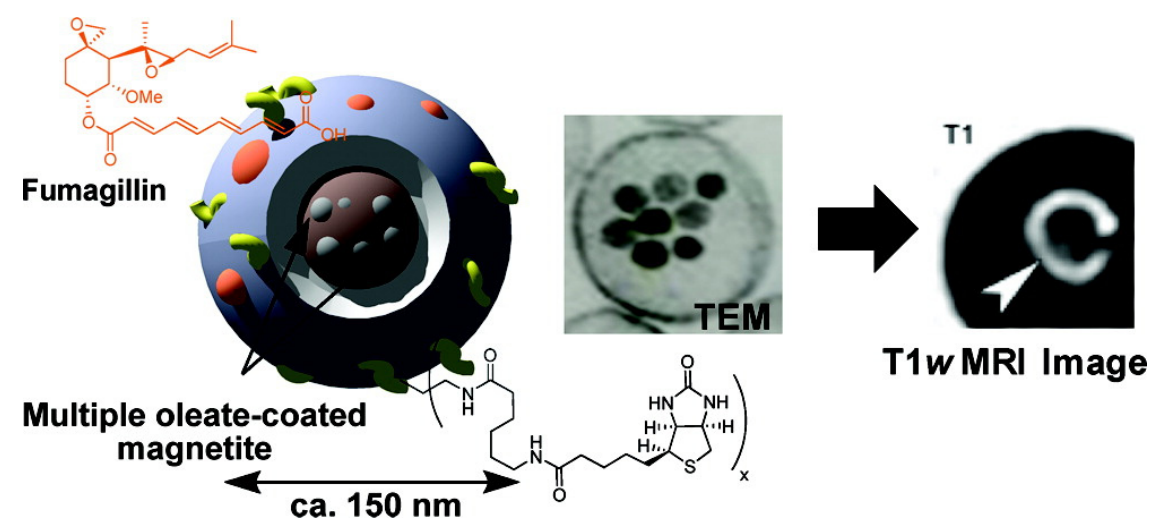

As a final example, we would like to highlight a recent contribution that makes use of one of the very well-known nanoparticles [179], IONPs coated with citric acid, which show selective accumulation in the calcifying microvesicles, characteristics of the atheroma lesion and also, to some extent, in the activated macrophages. All this makes these nanoparticles good candidates as probes for the study of the composition and inflammatory activity of the plaque at risk of destabilization.

\section{Conclusions}

The utility of nanotechnology in the study of cardiovascular diseases is currently fully demonstrated, from diagnosis to therapy. From the examples we have shown, it is clear that there are many examples of iron oxide-based particles able to diagnose and/or treat the atheroma plaque. For the next few years, the most difficult aspect that must be addressed is the applications of these nanoparticles in the clinic. For that to happen, one of the most important aspects is the development of reliable and reproducible methodologies allowing for the synthesis of the targeted nanoparticles we just saw. In our opinion, the best chances of achieving this goal is with the development of bio-orthogonal or chemo-selective approaches for the coupling of biologically-relevant compounds or drugs on the surface of IONPs. This kind of chemistry can deliver nano-compounds with controlled and specific composition on the surface. Moreover, it will allow for the binding of biomolecules with their intact native structure and function, assuring the best performance in terms of molecular imaging and disease treatment. This last point will also mean a clear advantage over the use of radionuclide-based probes for atherosclerosis, since, with a single radiation-free probe, the diagnosis, therapy and follow-up of the disease could be achieved. We consider that in the coming years, we will assist in the boom of this kind of functionalized nanoparticles in the field of cardiovascular imaging. 


\section{Acknowledgments}

The authors thank the Spanish Ministry of Science (SAF2011-25445), the Comunidad de Madrid (S2010/BMD-2326, Inmunothercan-CM, NANOCOPD-CIBERES-CIBERBBN-SEPAR), and the EU 7th Framework Program (FP7-PEOPLE-ITN-264864 Pinet and FP7-PEOPLE-2013-ITN CardioNext).

\section{Author Contributions}

Fernando Herranz, Beatriz Salinas and Jesús Ruiz-Cabello contributed to Sections 1, 2 and 5. Fernando Herranz, Hugo Groult, Juan Pellico and Riju Bhavesh. contributed to Section 3. Ana V. Lechuga-Vieco, Fernando Herranz and Jesús Ruiz-Cabello contributed to Section 4.

\section{Conflicts of Interest}

The authors declare no conflict of interest.

\section{References}

1. Ittrich, H.; Peldschus, K.; Raabe, N.; Kaul, M.; Adam, G. Superparamagnetic iron oxide nanoparticles in biomedicine: Applications and developments in diagnostics and therapy. RöFo Fortschritte Auf Dem Geb. Röntgenstrahlen Nukl. 2013, 185, 1149-1166.

2. Santhosh, P.B.; Ulrih, N.P. Multifunctional superparamagnetic iron oxide nanoparticles: Promising tools in cancer theranostics. Cancer Lett. 2013, 336, 8-17.

3. Wang, J.; Huang, Y.; David, A.E.; Chertok, B.; Zhang, L.; Yu, F.; Yang, V.C. Magnetic nanoparticles for MRI of brain tumors. Curr. Pharm. Biotechnol. 2012, 13, 2403-2416.

4. Kanwar, R.K.; Chaudhary, R.; Tsuzuki, T.; Kanwar, J.R. Emerging engineered magnetic nanoparticulate probes for molecular MRI of atherosclerosis: How far have we come? Nanomedicine 2012, 7, 899-916.

5. Chauveau, F.; Cho, T.H.; Berthezène, Y.; Nighoghossian, N.; Wiart, M. Imaging inflammation in stroke using magnetic resonance imaging. Int. J. Clin. Pharmacol. Ther. 2010, 48, 718-728.

6. Kanwar, R.K.; Chaudhary, R.; Tsuzuki, T.; Kanwar, J.R. Emerging engineered magnetic nanoparticulate probes for targeted MRI of atherosclerotic plaque macrophages. Nanomedicine 2012, 7, 735-749.

7. Kubinová, S.; Syková, E. Nanotechnology for treatment of stroke and spinal cord injury. Nanomedicine 2010, 5, 99-108.

8. Yilmaz, A.; Dengler, M.A.; van der Kuip, H.; Yildiz, H.; Rösch, S.; Klumpp, S.; Klingel, K.; Kandolf, R.; Helluy, X.; Hiller, K.-H.; et al. Imaging of myocardial infarction using ultrasmall superparamagnetic iron oxide nanoparticles: A human study using a multi-parametric cardiovascular magnetic resonance imaging approach. Eur. Heart J. 2013, 34, 462-475.

9. Maeda, H.; Nakamura, H.; Fang, J. The EPR effect for macromolecular drug delivery to solid tumors: Improvement of tumor uptake, lowering of systemic toxicity, and distinct tumor imaging in vivo. Adv. Drug Deliv. Rev. 2013, 65, 71-79.

10. Massart, R. Preparation of aqueous magnetic liquids in alkaline and acidic media. IEEE Trans. Magn. 1981, 17, 1247-1248. 
11. Lee, J.; Isobe, T.; Senna, M. Magnetic properties of ultrafine magnetite particles and their slurries prepared via in-situ precipitation. Colloids Surf. Physicochem. Eng. Asp. 1996, 109, 121-127.

12. Lee, S.-J.; Jeong, J.-R.; Shin, S.-C.; Kim, J.-C.; Kim, J.-D. Synthesis and characterization of superparamagnetic maghemite nanoparticles prepared by coprecipitation technique. J. Magn. Magn. Mater. 2004, 282, 147-150.

13. Sun, S.; Zeng, H. Size-controlled synthesis of magnetite nanoparticles. J. Am. Chem. Soc. 2002, 124, 8204-8205.

14. Li, Z.; Chen, H.; Bao, H.; Gao, M. One-pot reaction to synthesize water-soluble magnetite nanocrystals. Chem. Mater. 2004, 16, 1391-1393.

15. Rockenberger, J.; Scher, E.C.; Alivisatos, A.P. A new nonhydrolytic single-precursor approach to surfactant-capped nanocrystals of transition metal oxides. J. Am. Chem. Soc. 1999, 121, 11595-11596.

16. Kim, E.H.; Lee, H.S.; Kwak, B.K.; Kim, B.-K. Synthesis of ferrofluid with magnetic nanoparticles by sonochemical method for MRI contrast agent. J. Magn. Magn. Mater. 2005, 289, 328-330.

17. Suslick, K.S.; Fang, M.; Hyeon, T. Sonochemical synthesis of iron colloids. J. Am. Chem. Soc. 1996, 118, 11960-11961.

18. Yu, S.; Chow, G.M. Synthesis of monodisperse iron oxide and iron/iron oxide core/shell nanoparticles via iron-oleylamine complex. J. Nanosci. Nanotechnol. 2006, 6, 2135-2140.

19. Dai, Z.; Meiser, F.; Möhwald, H. Nanoengineering of iron oxide and iron oxide/silica hollow spheres by sequential layering combined with a sol-gel process. J. Colloid Interface Sci. 2005, 288, 298-300.

20. González-Carreño, T.; Morales, M.P.; Gracia, M.; Serna, C.J. Preparation of uniform $\gamma-\mathrm{Fe}_{2} \mathrm{O}_{3}$ particles with nanometer size by spray pyrolysis. Mater. Lett. 1993, 18, 151-155.

21. Veintemillas-Verdaguer, S.; Morales, M.; Serna, C. Continuous production of $\gamma-\mathrm{Fe}_{2} \mathrm{O}_{3}$ ultrafine powders by laser pyrolysis. Mater. Lett. 1998, 35, 227-231.

22. Morales, M.P.; Bomati-Miguel, O.; Pérez de Alejo, R.; Ruiz-Cabello, J.; Veintemillas-Verdaguer, S.; O'Grady, K. Contrast agents for MRI based on iron oxide nanoparticles prepared by laser pyrolysis. J. Magn. Magn. Mater. 2003, 266, 102-109.

23. Hyeon, T. Chemical synthesis of magnetic nanoparticles. Chem. Commun. 2003, 927-934.

24. Wang, J.; Sun, J.; Sun, Q.; Chen, Q. One-step hydrothermal process to prepare highly crystalline $\mathrm{Fe}_{3} \mathrm{O}_{4}$ nanoparticles with improved magnetic properties. Mater. Res. Bull. 2003, 38, 1113-1118.

25. Zheng, Y.; Cheng, Y.; Bao, F.; Wang, Y. Synthesis and magnetic properties of $\mathrm{Fe}_{3} \mathrm{O}_{4}$ nanoparticles. Mater. Res. Bull. 2006, 41, 525-529.

26. Mao, B.; Kang, Z.; Wang, E.; Lian, S.; Gao, L.; Tian, C.; Wang, C. Synthesis of magnetite octahedrons from iron powders through a mild hydrothermal method. Mater. Res. Bull. 2006, 41, 2226-2231.

27. Meldrum, F.; Heywood, B.; Mann, S. Magnetoferritin: In vitro synthesis of a novel magnetic protein. Science 1992, 257, 522-523.

28. Wong, K.K.W.; Douglas, T.; Gider, S.; Awschalom, D.D.; Mann, S. Biomimetic synthesis and characterization of magnetic proteins (magnetoferritin). Chem. Mater. 1998, 10, 279-285. 
29. Uchida, M.; Flenniken, M.L.; Allen, M.; Willits, D.A.; Crowley, B.E.; Brumfield, S.; Willis, A.F.; Jackiw, L.; Jutila, M.; Young, M.J.; et al. Targeting of cancer cells with ferrimagnetic ferritin cage nanoparticles. J. Am. Chem. Soc. 2006, 128, 16626-16633.

30. De Cuyper, M.; Joniau, M. Mechanistic aspects of the adsorption of phospholipids onto lauric acid stabilized magnetite nanocolloids. Langmuir 1991, 7, 647-652.

31. Pileni, M.-P. The role of soft colloidal templates in controlling the size and shape of inorganic nanocrystals. Nat. Mater. 2003, 2, 145-150.

32. Chin, A.B.; Yaacob, I.I. Synthesis and characterization of magnetic iron oxide nanoparticles via w/o microemulsion and Massart's procedure. J. Mater. Process. Technol. 2007, 191, 235-237.

33. Parsons, J.G.; Luna, C.; Botez, C.E.; Elizalde, J.; Gardea-Torresdey, J.L. Microwave-assisted synthesis of iron(III) oxyhydroxides/oxides characterized using transmission electron microscopy, X-ray diffraction, and X-ray absorption spectroscopy. J. Phys. Chem. Solids 2009, 70, 555-560.

34. Liao, X.; Zhu, J.; Zhong, W.; Chen, H.-Y. Synthesis of amorphous $\mathrm{Fe}_{2} \mathrm{O}_{3}$ nanoparticles by microwave irradiation. Mater. Lett. 2001, 50, 341-346.

35. Wang, W.-W.; Zhu, Y.-J.; Ruan, M.-L. Microwave-assisted synthesis and magnetic property of magnetite and hematite nanoparticles. J. Nanoparticle Res. 2006, 9, 419-426.

36. Jiang, F.Y.; Wang, C.M.; Fu, Y.; Liu, R.C. Synthesis of iron oxide nanocubes via microwave-assisted solvolthermal method. J. Alloys Compd. 2010, 503, L31-L33.

37. Sreeja, V.; Joy, P.A. Microwave-hydrothermal synthesis of $\gamma-\mathrm{Fe}_{2} \mathrm{O}_{3}$ nanoparticles and their magnetic properties. Mater. Res. Bull. 2007, 42, 1570-1576.

38. Khollam, Y.; Dhage, S.; Potdar, H.; Deshpande, S.; Bakare, P.; Kulkarni, S.; Date, S. Microwave hydrothermal preparation of submicron-sized spherical magnetite $\left(\mathrm{Fe}_{3} \mathrm{O}_{4}\right)$ powders. Mater. Lett. 2002, 56, 571-577.

39. Kim, D.K.; Zhang, Y.; Voit, W.; Rao, K.V.; Muhammed, M. Synthesis and characterization of surfactant-coated superparamagnetic monodispersed iron oxide nanoparticles. J. Magn. Magn. Mater. 2001, 225, 30-36.

40. Gazeau, F.; Bacri, J.; Gendron, F.; Perzynski, R.; Raikher, Y.; Stepanov, V.; Dubois, E. Magnetic resonance of ferrite nanoparticles: Evidence of surface effects. J. Magn. Magn. Mater. 1998, 186, $175-187$.

41. Gazeau, F.; Shilov, V.; Bacri, J.C.; Dubois, E.; Gendron, F.; Perzynski, R.; Raikher, Y.L.; Stepanov, V.I. Magnetic resonance of nanoparticles in a ferrofluid: Evidence of thermofluctuational effects. J. Magn. Magn. Mater. 1999, 202, 535-546.

42. Binh, V.T.; Purcell, S.T.; Semet, V.; Feschet, F. Nanotips and nanomagnetism. Appl. Surf. Sci. 1998, 130-132, 803-814.

43. Artemov, D.; Mori, N.; Okollie, B.; Bhujwalla, Z.M. MR molecular imaging of the Her-2/neu receptor in breast cancer cells using targeted iron oxide nanoparticles. Magn. Reson. Med. Off. J. Soc. Magn. Reson. Med. Soc. Magn. Reson. Med. 2003, 49, 403-408.

44. Jolivet, J.-P. Metal Oxide Chemistry and Synthesis: From Solution to Solid State; John Wiley: Chichester, NY, USA, 2000. 
45. Hadjipanayis, C.G.; Bonder, M.J.; Balakrishnan, S.; Wang, X.; Mao, H.; Hadjipanayis, G.C. Metallic iron nanoparticles for MRI contrast enhancement and local hyperthermia. Small 2008, 1925-1929.

46. Sjøgren, C.E.; Briley-Sæbø, K.; Hanson, M.; Johansson, C. Magnetic characterization of iron oxides for magnetic resonance imaging. Magn. Reson. Med. 1994, 31, 268-272.

47. Molday, R.S.; MacKenzie, D. Immunospecific ferromagnetic iron-dextran reagents for the labeling and magnetic separation of cells. J. Immunol. Methods 1982, 52, 353-367.

48. Berret, J.-F.; Schonbeck, N.; Gazeau, F.; El Kharrat, D.; Sandre, O.; Vacher, A.; Airiau, M. Controlled clustering of superparamagnetic nanoparticles using block copolymers: Design of new contrast agents for magnetic resonance imaging. J. Am. Chem. Soc. 2006, 128, 1755-1761.

49. Thünemann, A.F.; Schütt, D.; Kaufner, L.; Pison, U.; Möhwald, H. Maghemite nanoparticles protectively coated with poly(ethylene imine) and poly(ethylene oxide)-block-poly(glutamic acid). Langmuir ACS J. Surf. Colloids 2006, 22, 2351-2357.

50. Yoo, M.K.; Kim, I.Y.; Kim, E.M.; Jeong, H.-J.; Lee, C.-M.; Jeong, Y.Y.; Akaike, T.; Cho, C.S. Superparamagnetic iron oxide nanoparticles coated with galactose-carrying polymer for hepatocyte targeting. J. Biomed. Biotechnol. 2007, 10, doi:10.1155/2007/94740.

51. Shi, X.; Thomas, T.P.; Myc, L.A.; Kotlyar, A.; Baker, J.R., Jr. Synthesis, characterization, and intracellular uptake of carboxyl-terminated poly(amidoamine) dendrimer-stabilized iron oxide nanoparticles. Phys. Chem. Chem. Phys. 2007, 9, 5712-5720.

52. Shieh, D.-B.; Cheng, F.-Y.; Su, C.-H.; Yeh, C.-S.; Wu, M.-T.; Wu, Y.-N.; Tsai, C.-Y.; Wu, C.-L.; Chen, D.-H.; Chou, C.-H. Aqueous dispersions of magnetite nanoparticles with $\mathrm{NH}^{3+}$ surfaces for magnetic manipulations of biomolecules and MRI contrast agents. Biomaterials 2005, 26, 7183-7191.

53. Mohapatra, S.K.; Mahajan, V.K.; Misra, M. Double-side illuminated titania nanotubes for high volume hydrogen generation by water splitting. Nanotechnology 2007, 18, doi:10.1088/09574484/18/44/445705.

54. Sun, C.; Sze, R.; Zhang, M. Folic acid-PEG conjugated superparamagnetic nanoparticles for targeted cellular uptake and detection by MRI. J. Biomed. Mater. Res. A 2006, 78, 550-557.

55. Bee, A.; Massart, R.; Neveu, S. Synthesis of very fine maghemite particles. J. Magn. Magn. Mater. 1995, 149, 6-9.

56. Laurent, S.; Forge, D.; Port, M.; Roch, A.; Robic, C.; Vander Elst, L.; Muller, R.N. Magnetic iron oxide nanoparticles: synthesis, stabilization, vectorization, physicochemical characterizations, and biological applications. Chem. Rev. 2008, 108, 2064-2110.

57. Hyeon, T.; Lee, S.S.; Park, J.; Chung, Y.; Na, H.B. Synthesis of highly crystalline and monodisperse maghemite nanocrystallites without a size-selection process. J. Am. Chem. Soc. 2001, 123, 12798-12801.

58. Woo, K.; Hong, J.; Choi, S.; Lee, H.-W.; Ahn, J.-P.; Kim, C.S.; Lee, S.W. Easy synthesis and magnetic properties of iron oxide nanoparticles. Chem. Mater. 2004, 16, 2814-2818.

59. Park, J.; Lee, E.; Hwang, N.-M.; Kang, M.; Kim, S.C.; Hwang, Y.; Park, J.-G.; Noh, H.-J.; Kim, J.-Y.; Park, J.-H.; et al. One-nanometer-scale size-controlled synthesis of monodisperse magnetic iron oxide nanoparticles. Angew. Chem. Int. Ed. 2005, 44, 2872-2877. 
60. Murray, C.B.; Sun, S.; Gaschler, W.; Doyle, H.; Betley, T.A.; Kagan, C.R. Colloidal synthesis of nanocrystals and nanocrystal superlattices. IBM J. Res. Dev. 2001, 45, 47-56.

61. Park, J.; An, K.; Hwang, Y.; Park, J.-G.; Noh, H.-J.; Kim, J.-Y.; Park, J.-H.; Hwang, N.-M.; Hyeon, T. Ultra-large-scale syntheses of monodisperse nanocrystals. Nat. Mater. 2004, 3, 891-895.

62. Jana, N.R.; Chen, Y.; Peng, X. Size- and shape-controlled magnetic (Cr, Mn, Fe, Co, Ni) oxide nanocrystals via a simple and general approach. Chem. Mater. 2004, 16, 3931-3935.

63. Sun, S.; Zeng, H.; Robinson, D.B.; Raoux, S.; Rice, P.M.; Wang, S.X.; Li, G. Monodisperse $\mathrm{MFe}_{2} \mathrm{O}_{4}(\mathrm{M}=\mathrm{Fe}, \mathrm{Co}, \mathrm{Mn})$ Nanoparticles. J. Am. Chem. Soc. 2004, 126, 273-279.

64. Yu, W.W.; Falkner, J.C.; Yavuz, C.T.; Colvin, V.L. Synthesis of monodisperse iron oxide nanocrystals by thermal decomposition of iron carboxylate salts. Chem. Commun. 2004, 20, 2306-2306.

65. Qiao, R.; Yang, C.; Gao, M. Superparamagnetic iron oxide nanoparticles: From preparations to in vivo MRI applications. J. Mater. Chem. 2009, 19, 6274-6293.

66. Kwon, S.G.; Piao, Y.; Park, J.; Angappane, S.; Jo, Y.; Hwang, N.-M.; Park, J.-G.; Hyeon, T. Kinetics of monodisperse iron oxide nanocrystal formation by "heating-up" process. J. Am. Chem. Soc. 2007, 129, 12571-12584.

67. Cheon, J.; Kang, N.-J.; Lee, S.-M.; Lee, J.-H.; Yoon, J.-H.; Oh, S.J. Shape evolution of single-crystalline iron oxide nanocrystals. J. Am. Chem. Soc. 2004, 126, 1950-1951.

68. Tartaj, P.; del Puerto Morales, M; Veintemillas-Verdaguer, S.; González-Carreño, T.; Serna, C.J. The preparation of magnetic nanoparticles for applications in biomedicine. J. Phys. Appl. Phys. 2003, 36, R182-R197.

69. Yin, Y.; Alivisatos, A.P. Colloidal nanocrystal synthesis and the organic-inorganic interface. Nature 2005, 437, 664-670.

70. Bronstein, L.M.; Huang, X.; Retrum, J.; Schmucker, A.; Pink, M.; Stein, B.D.; Dragnea, B. Influence of iron oleate complex structure on iron oxide nanoparticle formation. Chem. Mater. 2007, 19, 3624-3632.

71. Hu, F.Q.; Wei, L.; Zhou, Z.; Ran, Y.L.; Li, Z.; Gao, M.Y. Preparation of biocompatible magnetite nanocrystals for in vivo magnetic resonance detection of cancer. Adv. Mater. 2006, 18, 2553-2556.

72. Hu, F.; Li, Z.; Tu, C.; Gao, M. Preparation of magnetite nanocrystals with surface reactive moieties by one-pot reaction. J. Colloid Interface Sci. 2007, 311, 469-474.

73. Lu, X.; Niu, M.; Qiao, R.; Gao, M. Superdispersible PVP-coated $\mathrm{Fe}_{3} \mathrm{O}_{4}$ nanocrystals prepared by a "one-pot" reaction. J. Phys. Chem. B 2008, 112, 14390-14394.

74. Ge, J.; Hu, Y.; Biasini, M.; Dong, C.; Guo, J.; Beyermann, W.P.; Yin, Y. One-step synthesis of highly water-soluble magnetite colloidal nanocrystals. Chem. Eur. J. 2007, 13, 7153-7161.

75. Cozzoli, P.D.; Snoeck, E.; Garcia, M.A.; Giannini, C.; Guagliardi, A.; Cervellino, A.; Gozzo, F.; Hernando, A.; Achterhold, K.; Ciobanu, N.; et al. Colloidal synthesis and characterization of tetrapod-shaped magnetic nanocrystals. Nano Lett. 2006, 6, 1966-1972.

76. Li, Z.; Sun, Q.; Gao, M. Preparation of water-soluble magnetite nanocrystals from hydrated ferric salts in 2-pyrrolidone: mechanism leading to $\mathrm{Fe}_{3} \mathrm{O}_{4}$. Angew. Chem. Int. Ed. 2005, 44, 123-126. 
77. Wan, J.; Cai, W.; Meng, X.; Liu, E. Monodisperse water-soluble magnetite nanoparticles prepared by polyol process for high-performance magnetic resonance imaging. Chem. Commun. 2007, 5004.

78. Jia, Q.; Zeng, J.; Qiao, R.; Jing, L.; Peng, L.; Gu, F.; Gao, M. Gelification: an effective measure for achieving differently sized biocompatible $\mathrm{Fe}_{3} \mathrm{O}_{4}$ nanocrystals through a single preparation recipe. J. Am. Chem. Soc. 2011, 133, 19512-19523.

79. Yang, D.-P.; Gao, F.; Cui, D.-X.; Yang, M. Microwave rapid synthesis of nanoporous $\mathrm{Fe}_{3} \mathrm{O}_{4}$ magnetic microspheres. Curr. Nanosci. 2009, 5, 485-488.

80. Osborne, E.A.; Atkins, T.M.; Gilbert, D.A.; Kauzlarich, S.M.; Liu, K.; Louie, A.Y. Rapid microwave-assisted synthesis of dextran-coated iron oxide nanoparticles for magnetic resonance imaging. Nanotechnology 2012, 23, 215602.

81. Wong, R.M.; Gilbert, D.A.; Liu, K.; Louie, A.Y. Rapid size-controlled synthesis of dextran-coated, ${ }^{64} \mathrm{Cu}$-doped iron oxide nanoparticles. ACS Nano 2012, 6, 3461-3467.

82. Liu, Y.; Welch, M.J. Nanoparticles labeled with positron emitting nuclides: Advantages, methods, and applications. Bioconjug. Chem. 2012, 23, 671-682.

83. Herranz, F.; Morales, M.P.; Roca, A.G.; Desco, M.; Ruiz-Cabello, J. A new method for the rapid synthesis of water stable superparamagnetic nanoparticles. Chem. Weinh. Bergstr. Ger. 2008, 14, 9126-9130.

84. Herranz, F.; Ruiz-Cabello, J.; Morales, M.P.; Roca, A.G.; Vilar, R. A new method for the aqueous functionalization of superparamagnetic $\mathrm{Fe}_{2} \mathrm{O}_{3}$ nanoparticles. Contrast Media Mol. Imaging 2008, 3, 215-222.

85. Herranz, F.; Schmidt-Weber, C.B.; Shamji, M.H.; Narkus, A.; Ruiz-Cabello, J.; Vilar, R. Superparamagnetic iron oxide nanoparticles conjugated to a grass pollen allergen and an optical probe. Contrast Media Mol. Imaging 2012, 7, 435-439.

86. Salinas, B.; Ruiz Cabello, J.; Morales, M.P.; Herranz, F. Olefin metathesis for the functionalization of superparamagnetic nanoparticles. Bioinspired Biomim. Nanobiomater. 2012, $1,166-172$.

87. Navani, N.K.; Sinha, S. Nanotechnology; Studium Press LLC: Houston, TX, USA, 2013; Volume 5.

88. Bloemen, M.; Brullot, W.; Luong, T.T.; Geukens, N.; Gils, A.; Verbiest, T. Improved functionalization of oleic acid-coated iron oxide nanoparticles for biomedical applications. J. Nanoparticle Res. 2012, 14, doi:10.1007/s11051-012-1100-5.

89. Sahoo, Y.; Pizem, H.; Fried, T.; Golodnitsky, D.; Burstein, L.; Sukenik, C.N.; Markovich, G. Alkyl phosphonate/phosphate coating on magnetite nanoparticles: A comparison with fatty acids. Langmuir 2001, 17, 7907-7911.

90. Sahoo, Y.; Goodarzi, A.; Swihart, M.T.; Ohulchanskyy, T.Y.; Kaur, N.; Furlani, E.P.; Prasad, P.N. Aqueous ferrofluid of magnetite nanoparticles: Fluorescence labeling and magnetophoretic control. J. Phys. Chem. B 2005, 109, 3879-3885.

91. Ma, D.; Guan, J.; Dénommée, S.; Enright, G.; Veres, T.; Simard, B. Multifunctional nano-architecture for biomedical applications. Chem. Mater. 2006, 18, 1920-1927. 
92. Deng, Y.-H.; Wang, C.-C.; Hu, J.-H.; Yang, W.-L.; Fu, S.-K. Investigation of formation of silica-coated magnetite nanoparticles via sol-gel approach. Colloids Surf. Physicochem. Eng. Asp. 2005, 262, 87-93.

93. Moghimi, S.M.; Hunter, A.C.; Murray, J.C. Long-circulating and target-specific nanoparticles: theory to practice. Pharmacol. Rev. 2001, 53, 283-318.

94. Lin, J.; Zhou, W.; Kumbhar, A.; Wiemann, J.; Fang, J.; Carpenter, E.E.; O’Connor, C.J. Gold-coated iron (Fe@Au) nanoparticles: Synthesis, characterization, and magnetic fieldinduced self-assembly. J. Solid State Chem. 2001, 159, 26-31.

95. Wu, W.; He, Q.; Jiang, C. Magnetic iron oxide nanoparticles: Synthesis and surface functionalization strategies. Nanoscale Res. Lett. 2008, 3, 397-415.

96. Na, H.B.; Lee, J.H.; An, K.; Park, Y.I.; Park, M.; Lee, I.S.; Nam, D.-H.; Kim, S.T.; Kim, S.-H.; Kim, S.-W.; et al. Development of a T1 contrast agent for magnetic resonance imaging using MnO nanoparticles. Angew. Chem. Int. Ed. Engl. 2007, 46, 5397-5401.

97. Roca, A.G.; Veintemillas-Verdaguer, S.; Port, M.; Robic, C.; Serna, C.J.; Morales, M.P. Effect of nanoparticle and aggregate size on the relaxometric properties of $\mathrm{mr}$ contrast agents based on high quality magnetite nanoparticles. J. Phys. Chem. B 2009, 113, 7033-7039.

98. de Palma, R.; Peeters, S.; van Bael, M.J.; van den Rul, H.; Bonroy, K.; Laureyn, W.; Mullens, J.; Borghs, G.; Maes, G. Silane ligand exchange to make hydrophobic superparamagnetic nanoparticles water-dispersible. Chem. Mater. 2007, 19, 1821-1831.

99. Onclin, S.; Ravoo, B.J.; Reinhoudt, D.N. Engineering silicon oxide surfaces using self-assembled monolayers. Angew. Chem. Int. Ed. 2005, 44, 6282-6304.

100. Sen, T.; Bruce, I.J. Surface engineering of nanoparticles in suspension for particle based bio-sensing. Sci. Rep. 2012, 2, doi:10.1038/srep00564.

101. Karimi, A.; Denizot, B.; Passirani, C.; Hindré, F.; Roux, J.; Legras, P.; le Jeune, J.J. In vitro and in vivo evaluation of superparamagnetic iron oxide nanoparticles coated by bisphosphonates: The effects of electrical charge and molecule length. Eur. J. Pharm. Sci. 2013, 49, 101-108.

102. Das, M.; Mishra, D.; Dhak, P.; Gupta, S.; Maiti, T.K.; Basak, A.; Pramanik, P. Biofunctionalized, phosphonate-grafted, ultrasmall iron oxide nanoparticles for combined targeted cancer therapy and multimodal imaging. Small 2009, 5, 2883-2893.

103. Mejías, R.; Pérez-Yagüe, S.; Roca, A.G.; Pérez, N.; Villanueva, A.; Cañete, M.; Mañes, S.; Ruiz-Cabello, J.; Benito, M.; Labarta, A.; et al. Liver and brain imaging through dimercaptosuccinic acid-coated iron oxide nanoparticles. Nanomedicine 2010, 5, 397-408.

104. Bagaria, H.G.; Ada, E.T.; Shamsuzzoha, M.; Nikles, D.E.; Johnson, D.T. Understanding mercapto ligand exchange on the surface of FePt nanoparticles. Langmuir 2006, 22, 7732-7737.

105. Duan, H.; Wang, D.; Sobal, N.S.; Giersig, M.; Kurth, D.G.; Möhwald, H. Magnetic colloidosomes derived from nanoparticle interfacial self-assembly. Nano Lett. 2005, 5, 949-952.

106. Daou, T.J.; Grenèche, J.M.; Pourroy, G.; Buathong, S.; Derory, A.; Ulhaq-Bouillet, C.; Donnio, B.; Guillon, D.; Begin-Colin, S. Coupling agent effect on magnetic properties of functionalized magnetite-based nanoparticles. Chem. Mater. 2008, 20, 5869-5875. 
107. Chattopadhyay, S.; Dash, S.K.; Ghosh, T.; Das, D.; Pramanik, P.; Roy, S. Surface modification of cobalt oxide nanoparticles using phosphonomethyl iminodiacetic acid followed by folic acid: A biocompatible vehicle for targeted anticancer drug delivery. Cancer Nanotechnol. 2013, 4, 103-116.

108. Majoros, I.J.; Myc, A.; Thomas, T.; Mehta, C.B.; Baker, J.R., Jr. PAMAM dendrimer-based multifunctional conjugate for cancer therapy: Synthesis, characterization, and functionality. Biomacromolecules 2006, 7, 572-579.

109. Duanmu, C.; Saha, I.; Zheng, Y.; Goodson, B.M.; Gao, Y. Dendron-functionalized superparamagnetic nanoparticles with switchable solubility in organic and aqueous media: matrices for homogeneous catalysis and potential mri contrast agents. Chem. Mater. 2006, 18, 5973-5981.

110. Zhang, T.; Ge, J.; Hu, Y.; Yin, Y. A general approach for transferring hydrophobic nanocrystals into water. Nano Lett. 2007, 7, 3203-3207.

111. Narain, R.; Gonzales, M.; Hoffman, A.S.; Stayton, P.S.; Krishnan, K.M. Synthesis of monodisperse biotinylated $\mathrm{p}$ (nipaam)-coated iron oxide magnetic nanoparticles and their bioconjugation to streptavidin. Langmuir 2007, 23, 6299-6304.

112. Xie, J.; Xu, C.; Kohler, N.; Hou, Y.; Sun, S. Controlled PEGylation of monodisperse $\mathrm{Fe}_{3} \mathrm{O}_{4}$ nanoparticles for reduced non-specific uptake by macrophage cells. Adv. Mater. 2007, 19, 3163-3166.

113. Kukowska-Latallo, J.F.; Candido, K.A.; Cao, Z.; Nigavekar, S.S.; Majoros, I.J.; Thomas, T.P.; Balogh, L.P.; Khan, M.K.; Baker, J.R., Jr. Nanoparticle targeting of anticancer drug improves therapeutic response in animal model of human epithelial cancer. Cancer Res. 2005, 65, 5317-5324.

114. Thomas, T.P.; Majoros, I.J.; Kotlyar, A.; Kukowska-Latallo, J.F.; Bielinska, A.; Myc, A.; Baker, J.R., Jr. Targeting and inhibition of cell growth by an engineered dendritic nanodevice. $J$. Med. Chem. 2005, 48, 3729-3735.

115. Rocha, N.; Mendes, J.; Durães, L.; Maleki, H.; Portugal, A.; Geraldes, C.F.G.C.; Serra, A.; Coelho, J. Poly(ethylene glycol)-block-poly(4-vinyl pyridine) as a versatile block copolymer to prepare nanoaggregates of superparamagnetic iron oxide nanoparticles. J. Mater. Chem. B 2014, 2, 1565-1575.

116. Park, Y.C.; Paulsen, J.; Nap, R.J.; Whitaker, R.D.; Mathiyazhagan, V.; Song, Y.-Q.; Hürlimann, M.; Szleifer, I.; Wong, J.Y. Adsorption of superparamagnetic iron oxide nanoparticles on silica and calcium carbonate sand. Langmuir 2014, 30, 784-792.

117. Wadajkar, A.S.; Menon, J.U.; Tsai, Y.-S.; Gore, C.; Dobin, T.; Gandee, L.; Kangasniemi, K.; Takahashi, M.; Manandhar, B.; Ahn, J.-M.; et al. Prostate cancer-specific thermo-responsive polymer-coated iron oxide nanoparticles. Biomaterials 2013, 34, 3618-3625.

118. Jain, T.K.; Morales, M.A.; Sahoo, S.K.; Leslie-Pelecky, D.L.; Labhasetwar, V. Iron oxide nanoparticles for sustained delivery of anticancer agents. Mol. Pharm. 2005, 2, 194-205.

119. Yu, W.W.; Chang, E.; Sayes, C.M.; Drezek, R.; Colvin, V.L. Aqueous dispersion of monodisperse magnetic iron oxide nanocrystals through phase transfer. Nanotechnology 2006, 17, 4483 . 
120. Qin, J.; Laurent, S.; Jo, Y.S.; Roch, A.; Mikhaylova, M.; Bhujwalla, Z.M.; Muller, R.N.; Muhammed, M. A high-performance magnetic resonance imaging T2 contrast agent. Adv. Mater. 2007, 19, 1874-1878.

121. Chen, Y.-J.; Tao, J.; Xiong, F.; Zhu, J.-B.;Gu, N.; Zhang, Y.-H.; Ding, Y.; Ge, L. Synthesis, self-assembly, and characterization of PEG-coated iron oxide nanoparticles as potential MRI contrast agent. Drug Dev. Ind. Pharm. 2010, 36, 1235-1244.

122. Nasongkla, N.; Bey, E.; Ren, J.; Ai, H.; Khemtong, C.; Guthi, J.S.; Chin, S.-F.; Sherry, A.D.; Boothman, D.A.; Gao, J. Multifunctional polymeric micelles as cancer-targeted, mri-ultrasensitive drug delivery systems. Nano Lett. 2006, 6, 2427-2430.

123. Jain, T.K.; Foy, S.P.; Erokwu, B.; Dimitrijevic, S.; Flask, C.A.; Labhasetwar, V. Magnetic resonance imaging of multifunctional pluronic stabilized iron-oxide nanoparticles in tumor-bearing mice. Biomaterials 2009, 30, 6748-6756.

124. Li, Y.; Ma, J.; Zhu, H.; Gao, X.; Dong, H.; Shi, D. Green synthetic, multifunctional hybrid micelles with shell embedded magnetic nanoparticles for theranostic applications. ACS Appl. Mater. Interfaces 2013, 5, 7227-7235.

125. Huang, C.; Tang, Z.; Zhou, Y.; Zhou, X.; Jin, Y.; Li, D.; Yang, Y.; Zhou, S. Magnetic micelles as a potential platform for dual targeted drug delivery in cancer therapy. Int. J. Pharm. 2012, $429,113-122$.

126. Lin, J.-J.; Chen, J.-S.; Huang, S.-J.; Ko, J.-H.; Wang, Y.-M.; Chen, T.-L.; Wang, L.-F. Folic acid-Pluronic F127 magnetic nanoparticle clusters for combined targeting, diagnosis, and therapy applications. Biomaterials 2009, 30, 5114-5124.

127. Bronstein, L.M.; Shtykova, E.V.; Malyutin, A.; Dyke, J.C.; Gunn, E.; Gao, X.; Stein, B.; Konarev, P.V.; Dragnea, B.; Svergun, D.I. Hydrophilization of magnetic nanoparticles with modified alternating copolymers. Part 1: The influence of the grafting. J. Phys. Chem. C Nanomater. Interfaces 2010, 114, 21900-21907.

128. Su, H.; Liu, Y.; Wang, D.; Wu, C.; Xia, C.; Gong, Q.; Song, B.; Ai, H. Amphiphilic starlike dextran wrapped superparamagnetic iron oxide nanoparticle clsuters as effective magnetic resonance imaging probes. Biomaterials 2013, 34, 1193-1203.

129. Huang, H.-C.; Chang, P.-Y.; Chang, K.; Chen, C.-Y.; Lin, C.-W.; Chen, J.-H.; Mou, C.-Y.; Chang, Z.-F.; Chang, F.-H. Formulation of novel lipid-coated magnetic nanoparticles as the probe for in vivo imaging. J. Biomed. Sci. 2009, 16, 86.

130. Erogbogbo, F.; Yong, K.-T.; Hu, R.; Law, W.-C.; Ding, H.; Chang, C.-W.; Prasad, P.N.; Swihart, M.T. Biocompatible magnetofluorescent probes: luminescent silicon quantum dots coupled with superparamagnetic iron(III) oxide. ACS Nano 2010, 4, 5131-5138.

131. Kim, B.-S.; Qiu, J.-M.; Wang, J.-P.; Taton, T.A. Magnetomicelles: Composite nanostructures from magnetic nanoparticles and cross-linked amphiphilic block copolymers. Nano Lett. 2005, 5, 1987-1991.

132. Zhu, J.; Hayward, R.C. Spontaneous generation of amphiphilic block copolymer micelles with multiple morphologies through interfacial instabilities. J. Am. Chem. Soc. 2008, 130, 7496-7502.

133. Hickey, R.J.; Haynes, A.S.; Kikkawa, J.M.; Park, S.-J. Controlling the self-assembly structure of magnetic nanoparticles and amphiphilic block-copolymers: from micelles to vesicles. J. Am. Chem. Soc. 2011, 133, 1517-1525. 
134. Pellegrino, T.; Manna, L.; Kudera, S.; Liedl, T.; Koktysh, D.; Rogach, A.L.; Keller, S.; Rädler, J.; Natile, G.; Parak, W.J. Hydrophobic nanocrystals coated with an amphiphilic polymer shell: A general route to water soluble nanocrystals. Nano Lett. 2004, 4, 703-707.

135. Xie, J.; Peng, S.; Brower, N.; Pourmand, N.; Wang, S.X.; Sun, S. One-pot synthesis of monodisperse iron oxide nanoparticles for potential biomedical applications. Pure Appl. Chem. 2006, 78, 1003-1014.

136. Park, J.; Yu, M.K.; Jeong, Y.Y.; Kim, J.W.; Lee, K.; Phan, V.N.; Jon, S. Antibiofouling amphiphilic polymer-coated superparamagnetic iron oxide nanoparticles: Synthesis, characterization, and use in cancer imaging in vivo. J. Mater. Chem. 2009, 19, 6412.

137. Quarta, A.; Curcio, A.; Kakwere, H.; Pellegrino, T. Polymer coated inorganic nanoparticles: Tailoring the nanocrystal surface for designing nanoprobes with biological implications. Nanoscale 2012, 4, 3319.

138. Wang, L.; Neoh, K.-G.; Kang, E.-T.; Shuter, B.; Wang, S.-C. Biodegradable magnetic-fluorescent magnetite/poly(dl-lactic acid-co- $\alpha, \beta$-malic acid) composite nanoparticles for stem cell labeling. Biomaterials 2010, 31, 3502-3511.

139. Ai, H.; Flask, C.; Weinberg, B.; Shuai, X.-T.; Pagel, M.D.; Farrell, D.; Duerk, J.; Gao, J. Magnetite-loaded polymeric micelles as ultrasensitive magnetic-resonance probes. Adv. Mater. 2005, 17, 1949-1952.

140. Hong, G.-B.; Zhou, J.-X.; Yuan, R.X. Folate-targeted polymeric micelles loaded with ultrasmall superparamagnetic iron oxide: combined small size and high MRI sensitivity. Int. J. Nanomedicine 2012, 7, 2863-2872.

141. Boni, A.; Albertazzi, L.; Innocenti, C.; Gemmi, M.; Bifone, A. Water dispersal and functionalization of hydrophobic iron oxide nanoparticles with lipid-modified poly(amidoamine) dendrimers. Langmuir ACS J. Surf. Colloids 2013, 29, 10973-10979.

142. Mulder, W.J.M.; Strijkers, G.J.; van Tilborg, G.A.F.; Cormode, D.P.; Fayad, Z.A.; Nicolay, K. Nanoparticulate assemblies of amphiphiles and diagnostically active materials for multimodality imaging. Acc. Chem. Res. 2009, 42, 904-914.

143. Torchilin, V.P. Recent advances with liposomes as pharmaceutical carriers. Nat. Rev. Drug Discov. 2005, 4, 145-160.

144. Allen, T.M.; Cullis, P.R. Liposomal drug delivery systems: From concept to clinical applications. Adv. Drug Deliv. Rev. 2013, 65, 36-48.

145. Skouras, A.; Mourtas, S.; Markoutsa, E.; De Goltstein, M.-C.; Wallon, C.; Catoen, S.; Antimisiaris, S.G. Magnetoliposomes with high USPIO entrapping efficiency, stability and magnetic properties. Nanomed. Nanotechnol. Biol. Med. 2011, 7, 572-579.

146. Martina, M.-S.; Fortin, J.-P.; Ménager, C.; Clément, O.; Barratt, G.; Grabielle-Madelmont, C.; Gazeau, F.; Cabuil, V.; Lesieur, S. Generation of superparamagnetic liposomes revealed as highly efficient MRI contrast agents for in vivo imaging. J. Am. Chem. Soc. 2005, 127, 10676-10685.

147. Soenen, S.J.; Velde, G.V.; Ketkar-Atre, A.; Himmelreich, U.; de Cuyper, M. Magnetoliposomes as magnetic resonance imaging contrast agents. Wiley Interdiscip. Rev. Nanomed. Nanobiotechnol. 2011, 3, 197-211. 
148. Cormode, D.P.; Skajaa, T.; van Schooneveld, M.M.; Koole, R.; Jarzyna, P.; Lobatto, M.E.; Calcagno, C.; Barazza, A.; Gordon, R.E.; Zanzonico, P.; et al. Nanocrystal core high-density lipoproteins: A multimodality contrast agent platform. Nano Lett. 2008, 8, 3715-3723.

149. Lin, Y.A.; Boutureira, O.; Lercher, L.; Bhushan, B.; Paton, R.S.; Davis, B.G. Rapid cross-metathesis for reversible protein modifications via chemical access to Se-allyl-selenocysteine in proteins. J. Am. Chem. Soc. 2013, 135, 12156-12159.

150. Herranz, F.; Almarza, E.; Rodríguez, I.; Salinas, B.; Rosell, Y.; Desco, M.; Bulte, J.W.; Ruiz-Cabello, J. The application of nanoparticles in gene therapy and magnetic resonance imaging. Microsc. Res. Tech. 2011, 74, 577-591.

151. Lin, Y.A.; Chalker, J.M.; Davis, B.G. Olefin cross-metathesis on proteins: Investigation of allylic chalcogen effects and guiding principles in metathesis partner selection. J. Am. Chem. Soc. 2010, 132, 16805-16811.

152. Briley-Saebo, K.C.; Mulder, W.J.M.; Mani, V.; Hyafil, F.; Amirbekian, V.; Aguinaldo, J.G.S.; Fisher, E.A.; Fayad, Z.A. Magnetic resonance imaging of vulnerable atherosclerotic plaques: Current imaging strategies and molecular imaging probes. J. Magn. Reson. Imaging 2007, 26, 460-479.

153. McAteer, M.A.; Akhtar, A.M.; von zur Muhlen, C.; Choudhury, R.P. An approach to molecular imaging of atherosclerosis, thrombosis, and vascular inflammation using microparticles of iron oxide. Atherosclerosis 2010, 209, 18-27.

154. Ross, R. Atherosclerosis — an inflammatory disease. N. Engl. J. Med. 1999, 340, 115-126.

155. Sanz, J.; Fayad, Z.A. Imaging of atherosclerotic cardiovascular disease. Nature 2008, 451, 953-957.

156. Wildgruber, M. Molecular imaging of inflammation in atherosclerosis. Theranostics 2013, 3, 865-884.

157. Corti, R.; Fuster, V. Imaging of atherosclerosis: Magnetic resonance imaging. Eur. Heart J. 2011, 32, 1709-1719.

158. Sanz, J.; Moreno, P.R.; Fuster, V. The year in atherothrombosis. J. Am. Coll. Cardiol. 2012, 60, 932-942.

159. Otsuka, F.; Fuster, V.; Narula, J.; Virmani, R. Omnipresent atherosclerotic disease: Time to depart from analysis of individual vascular beds. Mt. Sinai J. Med. N.Y. 2012, 79, 641-653.

160. Dutta, P.; Courties, G.; Wei, Y.; Leuschner, F.; Gorbatov, R.; Robbins, C.S.; Iwamoto, Y.; Thompson, B.; Carlson, A.L.; Heidt, T.; et al. Myocardial infarction accelerates atherosclerosis. Nature 2012, 487, 325-329.

161. Hermann, S.; Starsichova, A.; Waschkau, B.; Kuhlmann, M.; Wenning, C.; Schober, O.; Schäfers, M. Non-FDG imaging of atherosclerosis: Will imaging of MMPs assess plaque vulnerability? J. Nucl. Cardiol. 2012, 19, 609-617.

162. Sadeghi, M.M.; Glover, D.K.; Lanza, G.M.; Fayad, Z.A.; Johnson, L.L. Imaging atherosclerosis and vulnerable plaque. J. Nucl. Med. 2010, 51, 51S-65S.

163. Sosnovik, D.E.; Nahrendorf, M.; Weissleder, R. Magnetic nanoparticles for MR imaging: Agents, techniques and cardiovascular applications. Basic Res. Cardiol. 2008, 103, 122-130. 
164. Schmitz, S.A.; Coupland, S.E.; Gust, R.; Winterhalter, S.; Wagner, S.; Kresse, M.; Semmler, W.; Wolf, K.J. Superparamagnetic iron oxide-enhanced MRI of atherosclerotic plaques in Watanabe hereditable hyperlipidemic rabbits. Invest. Radiol. 2000, 35, 460-471.

165. Schmitz, S.A.; Taupitz, M.; Wagner, S.; Wolf, K.J.; Beyersdorff, D.; Hamm, B. Magnetic resonance imaging of atherosclerotic plaques using superparamagnetic iron oxide particles. J. Magn. Reson. Imaging 2001, 14, 355-361.

166. Ruehm, S.G.; Corot, C.; Vogt, P.; Kolb, S.; Debatin, J.F. Magnetic resonance imaging of atherosclerotic plaque with ultrasmall superparamagnetic particles of iron oxide in hyperlipidemic rabbits. Circulation 2001, 103, 415-422.

167. Schmitz, S.A.; Taupitz, M.; Wagner, S.; Coupland, S.E.; Gust, R.; Nikolova, A.; Wolf, K.J. Iron-oxide-enhanced magnetic resonance imaging of atherosclerotic plaques: Postmortem analysis of accuracy, inter-observer agreement, and pitfalls. Invest. Radiol. 2002, 37, 405-411.

168. Kooi, M.E.; Cappendijk, V.C.; Cleutjens, K.B.J.M.; Kessels, A.G.H.; Kitslaar, P.J.E.H.M.; Borgers, M.; Frederik, P.M.; Daemen, M.J.A.P.; van Engelshoven, J.M.A. Accumulation of ultrasmall superparamagnetic particles of iron oxide in human atherosclerotic plaques can be detected by in vivo magnetic resonance imaging. Circulation 2003, 107, 2453-2458.

169. Schmitz, S.A.; Winterhalter, S.; Schiffler, S.; Gust, R.; Wagner, S.; Kresse, M.; Coupland, S.E.; Semmler, W.; Wolf, K.-J. USPIO-enhanced direct $\mathrm{mr}$ imaging of thrombus: Preclinical evaluation in rabbits 1. Radiology 2001, 221, 237-243.

170. Tang, T.Y.; Muller, K.H.; Graves, M.J.; Li, Z.Y.; Walsh, S.R.; Young, V.; Sadat, U.; Howarth, S.P.S.; Gillard, J.H. Iron oxide particles for atheroma imaging. Arterioscler. Thromb. Vasc. Biol. 2009, 29, 1001-1008.

171. Satomi, T.; Ogawa, M.; Mori, I.; Ishino, S.; Kubo, K.; Magata, Y.; Nishimoto, T. Comparison of contrast agents for atherosclerosis imaging using cultured macrophages: FDG versus ultrasmall superparamagnetic iron oxide. J. Nucl. Med. 2013, 54, 999-1004.

172. Segers, F.M.E.; den Adel, B.; Bot, I.; van der Graaf, L.M.; van der Veer, E.P.; Gonzalez, W.; Raynal, I.; de Winther, M.; Wodzig, W.K.; Poelmann, R.E.; et al. Scavenger receptor-ai-targeted iron oxide nanoparticles for in vivo MRI detection of atherosclerotic lesions. Arterioscler. Thromb. Vasc. Biol. 2013, 33, 1812-1819.

173. Kelly, K.A. Detection of vascular adhesion molecule-1 expression using a novel multimodal nanoparticle. Circ. Res. 2005, 96, 327-336.

174. Nahrendorf, M.; Jaffer, F.A.; Kelly, K.A.; Sosnovik, D.E.; Aikawa, E.; Libby, P.; Weissleder, R. Noninvasive vascular cell adhesion molecule-1 imaging identifies inflammatory activation of cells in atherosclerosis. Circulation 2006, 114, 1504-1511.

175. Woollard, K.J.; Chin-Dusting, J. Therapeutic targeting of p-selectin in atherosclerosis. Inflamm. Allergy Drug Targets 2007, 6, 69-74.

176. Jacobin-Valat, M.-J.; Deramchia, K.; Mornet, S.; Hagemeyer, C.E.; Bonetto, S.; Robert, R.; Biran, M.; Massot, P.; Miraux, S.; Sanchez, S.; et al. MRI of inducible P-selectin expression in human activated platelets involved in the early stages of atherosclerosis. NMR Biomed. 2011, 24, 413-424. 
177. Smith, B.R.; Heverhagen, J.; Knopp, M.; Schmalbrock, P.; Shapiro, J.; Shiomi, M.; Moldovan, N.I.; Ferrari, M.; Lee, S.C. Localization to atherosclerotic plaque and biodistribution of biochemically derivatized superparamagnetic iron oxide nanoparticles (SPIONs) contrast particles for magnetic resonance imaging (MRI). Biomed. Microdevices 2007, 9, 719-727.

178. Senpan, A.; Caruthers, S.D.; Rhee, I.; Mauro, N.A.; Pan, D.; Hu, G.; Scott, M.J.; Fuhrhop, R.W.; Gaffney, P.J.; Wickline, S.A.; et al. Conquering the dark side: Colloidal iron oxide nanoparticles. ACS Nano 2009, 3, 3917-3926.

179. Wagner, S.; Schnorr, J.; Ludwig, A.; Stangl, V.; Ebert, M.; Hamm, B; Taupitz, M. Contrast-enhanced MR imaging of atherosclerosis using citrate-coated superparamagnetic iron oxide nanoparticles: Calcifying microvesicles as imaging target for plaque characterization. Int. J. Nanomedicine 2013, 8, 767-779.

(C) 2014 by the authors; licensee MDPI, Basel, Switzerland. This article is an open access article distributed under the terms and conditions of the Creative Commons Attribution license (http://creativecommons.org/licenses/by/3.0/). 